\title{
Metal-ion rescue revisited: Biochemical detection of site-bound metal ions important for RNA folding
}

\author{
JOHN K. FREDERIKSEN, ${ }^{1,2,5}$ NAN-SHENG LI, ${ }^{2,3}$ RHIJU DAS, ${ }^{4,6}$ DANIEL HERSCHLAG, ${ }^{4,6}$ \\ and JOSEPH A. PICCIRILLI ${ }^{2,3,6}$ \\ ${ }^{1}$ The Pritzker School of Medicine, ${ }^{2}$ Department of Biochemistry and Molecular Biology, ${ }^{3}$ Department of Chemistry, The University of Chicago, \\ Chicago, Illinois 60637, USA \\ ${ }^{4}$ Department of Biochemistry, Beckman Center, Stanford University, Stanford, California 94305-5307, USA
}

\begin{abstract}
Within the three-dimensional architectures of RNA molecules, divalent metal ions populate specific locations, shedding their water molecules to form chelates. These interactions help the RNA adopt and maintain specific conformations and frequently make essential contributions to function. Defining the locations of these site-bound metal ions remains challenging despite the growing database of RNA structures. Metal-ion rescue experiments have provided a powerful approach to identify and distinguish catalytic metal ions within RNA active sites, but the ability of such experiments to identify metal ions that contribute to tertiary structure acquisition and structural stability is less developed and has been challenged. Herein, we use the well-defined P4-P6 RNA domain of the Tetrahymena group I intron to reevaluate prior evidence against the discriminatory power of metal-ion rescue experiments and to advance thermodynamic descriptions necessary for interpreting these experiments. The approach successfully identifies ligands within the RNA that occupy the inner coordination sphere of divalent metal ions and distinguishes them from ligands that occupy the outer coordination sphere. Our results underscore the importance of obtaining complete folding isotherms and establishing and evaluating thermodynamic models in order to draw conclusions from metal-ion rescue experiments. These results establish metal-ion rescue as a rigorous tool for identifying and dissecting energetically important metal-ion interactions in RNAs that are noncatalytic but critical for RNA tertiary structure.
\end{abstract}

Keywords: diffuse ion atmosphere; metal-ion rescue; phosphorothioate; RNA; RNA structure and folding

\section{INTRODUCTION}

When RNA molecules adopt compact three-dimensional architectures, the negative charge of the ribose-phosphate backbone generates enormous repulsive energy. Counteracting this repulsion, cations condense onto all RNA molecules, forming a counterion atmosphere (Manning 1977a, 1978; Bukhman and Draper 1997; Misra and Draper 1998; Das et al. 2005b; Draper et al. 2005; Chu et al. 2008; Leipply et al. 2009). While the vast majority of cations associated with RNA reside in this diffuse ion atmosphere, some ions associate more intimately with the RNA, using their hydra-

\footnotetext{
${ }^{5}$ Present address: Department of Pathology and Laboratory Medicine, The University of Rochester Medical Center, Rochester, NY 14642, USA.

${ }^{6}$ Corresponding authors.

E-mail jpicciri@uchicago.edu.

E-mail herschla@stanford.edu.

E-mail rhiju@stanford.edu.

Article published online ahead of print. Article and publication date are at http://www.rnajournal.org/cgi/doi/10.1261/rna.028738.111.
}

tion shells to bind to specific sites via hydrogen bonding (outer-sphere coordination) or shedding water molecules to coordinate directly to an RNA heteroatom (inner-sphere coordination). These site-bound metal ions often appear in intricate structures within folded RNAs and, in the case of several ribozymes, participate directly in catalysis (Chen et al. 1997; Sontheimer et al. 1997; Shan et al. 1999; Gordon et al. 2007). Accordingly, understanding RNA structure and function requires knowing the locations of site-bound metal ions and the thermodynamics of their interactions with RNA.

Metal-ion rescue experiments, first used to delineate metal-ion substrate interactions in protein enzyme active sites (Jaffe and Cohn 1978; Darby and Trayer 1983; Lee and O’Sullivan 1985; Pecoraro et al. 1985), have been expanded in ribozyme studies to provide a powerful strategy to identify individual metal ions, define their ligands, and assign their roles in catalysis (Piccirilli et al. 1993; Chen et al. 1997; Sontheimer et al. 1997; Weinstein et al. 1997; Shan et al. 1999; Yoshida et al. 1999; Hougland et al. 2005; Gordon 
et al. 2007; Forconi et al. 2008; Forconi and Herschlag 2009). The rescue approach relies on the differential preferences of $\mathrm{Mg}^{2+}$ and "softer" divalent metal ions like $\mathrm{Mn}^{2+}, \mathrm{Cd}^{2+}$, and $\mathrm{Zn}^{2+}$ to coordinate oxygen vs. sulfur or nitrogen ligands. As $\mathrm{Mg}^{2+}$ coordinates these ligands more weakly than it coordinates oxygen, sulfur or nitrogen substitution of an oxygen ligand can disrupt the $\mathrm{Mg}^{2+}$ interaction, leading to deleterious effects on activity. Inclusion of cations that interact more strongly than $\mathrm{Mg}^{2+}$ with sulfur or nitrogen often restores the disrupted interaction, resulting in suppression of the deleterious effect, or "rescue." In practice, these experiments require quantitative analysis of the energetic effects of the substitution in the presence of $\mathrm{Mg}^{2+}$ and in the presence of the rescuing cation $\mathrm{M}^{2+}$ to provide the most reliable and extensive information about the number of bound metal ions and their interactions (Shan et al. 1999; Wang et al. 1999; Christian 2005; Forconi and Herschlag 2009).

In principle, this metal-ion rescue approach should also be a powerful biochemical tool for identifying metal-ion sites important for folding and conformational transitions in structured and signaling RNA molecules. However, a previous study of sulfur interferences in the independently folding P4-P6 RNA domain did not correspond well with structural data (Basu and Strobel 1999). Using a nondenaturing gel electrophoresis assay that probes the fraction of folded RNA by the differential migration of compact and extended forms, a population of P4-P6 RNAs containing a random distribution of $R_{\mathrm{P}}$-phosphorothioates was screened to identify sites within the domain where $R_{\mathrm{P}}$-phosphorothioate substitution interferes with global compaction (Cate et al. 1997; Basu and Strobel 1999). The identified sites included a subset of the ligands for metal ions observed crystallographically. Within this subset, $\mathrm{Mn}^{2+}$ and other soft metal ions suppressed phosphorothioate interference of global compaction at some, but not all, inner-sphere ligands (Basu and Strobel 1999). In addition, $\mathrm{Mn}^{2+}$ apparently suppressed phosphorothioate interference of folding by two outer-sphere ligands, a result that called into question the usual inference that metal-ion rescue reveals sites of inner-sphere coordination (Basu and Strobel 1999).

The apparent outer-sphere rescue could have major implications for published and future studies applying metal-ion rescue approaches to both RNA catalysis and RNA conformational transitions. Consequently, we sought to determine whether these results in the P4-P6 RNA identified a fundamental limitation of metal-ion rescue or a limitation of the study's methodology and analysis. Addressing these issues successfully could establish proof-of-concept for adapting the rescue approach to the investigation of metal ions in nonenzymatic, noncoding RNAs (ncRNAs), which likely encompass the vast majority of metal-ion binding sites within the cellular RNAome (Costa 2010).

We have synthesized variants of P4-P6 RNA bearing phosphorothioate modifications at specific locations and used hydroxyl radical footprinting to characterize the $\mathrm{Mg}^{2+}$ and $\mathrm{Mn}^{2+}$-induced folding transitions of these variants. Rescue is observed at positions identified as inner sphere in the P4-P6 crystal structures, but not at outer-sphere positions. These results clarify limitations of prior metal-ion rescue experiments and provide strong support for the power of the approach for investigating RNA folding and conformational changes, as well as a rigorous template for carrying out such studies.

\section{RESULTS AND DISCUSSION}

\section{The "standard" thermodynamic framework for RNA folding and metal-ion rescue}

For metal-ion rescue and other experiments that probe interactions, one would ideally make direct comparisons of free energies via thermodynamic cycles. A thermodynamic cycle for folding of unmodified and thio-modified P4-P6 ( $\mathrm{O}$ and $\mathrm{S}$, respectively) in the presence of $\mathrm{Mg}^{2+}$ or $\mathrm{Mn}^{2+}$ is shown in Scheme 1A, and the folding free energies are compared via the $\Delta \Delta G$ values defined in Scheme 1B. Rescue would correspond to the observation of amelioration of a folding defect-an increase in $\Delta \mathrm{G}_{\text {fold }}$ (less favorable folding) for folding of the thio-substituted RNA in $\mathrm{Mg}^{2+}$ that is alleviated in the presence of a softer metal ion such as $\mathrm{Mn}^{2+}$ (Scheme 1B). In terms of the free energies defined in Scheme $1 \mathrm{~B}$, if folding is affected similarly in $\mathrm{Mg}^{2+}$ and $\mathrm{Mn}^{2+}$, no rescue occurs $\left(\Delta \Delta \Delta \mathrm{G}_{\text {rescue }}=0\right)$, whereas a positive value of $\Delta \Delta \Delta \mathrm{G}_{\text {rescue }}$ would indicate rescue.

Evaluating metal-ion rescue quantitatively therefore requires estimating free energies of folding. RNA folding is typically followed as a function of metal-ion concentration, with different RNAs exhibiting different folding transitions. For each RNA, the experimentally observed "fraction folded" is typically fit to the Hill model:

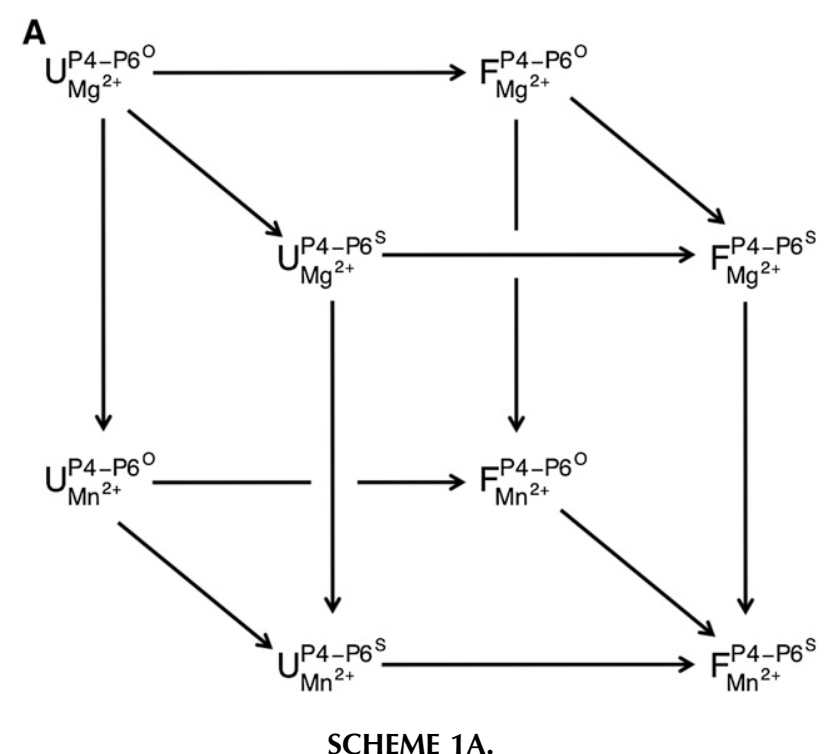


B

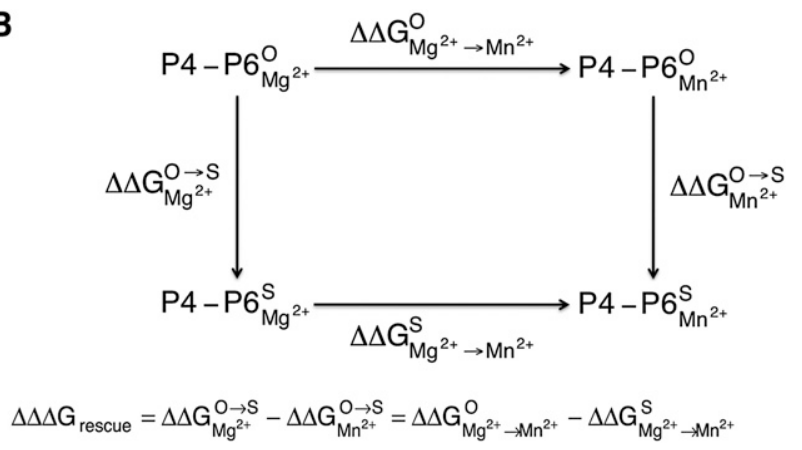

SCHEME 1B.

$$
\text { Fraction folded }=\frac{\left(\frac{\left[\mathrm{M}^{2+}\right]}{\left[\mathrm{M}^{2+}\right]_{1 / 2}}\right)^{n}}{1+\left(\frac{\left[\mathrm{M}^{2+}\right]}{\left[\mathrm{M}^{2+}\right]_{1 / 2}}\right)^{n}} .
$$

Here, $\left[\mathrm{M}^{2+}\right]$ is the metal-ion concentration, and $\left[\mathrm{M}^{2+}\right]_{1 / 2}$ and $n$ are the transition midpoint and apparent Hill coefficient, respectively (Fang et al. 1999; Rook et al. 1999; Das et al. 2005b). This model corresponds to a free-energy difference between the unfolded and folded state of

$$
\Delta \mathrm{G}=-n R T \ln \left(\frac{\left[\mathrm{M}^{2+}\right]}{\left[\mathrm{M}^{2+}\right]_{1 / 2}}\right),
$$

where $R$ is the gas constant and $T$ is the temperature. Values for "fraction folded" are readily determined for $\left[\mathrm{M}^{2+}\right]$ around the transition midpoints' $\left[\mathrm{M}^{2+}\right]_{1 / 2}$ values, but extrapolation of inferred folding free energies to higher and lower metal-ion concentrations is necessary to compare RNA variants with different stabilities. If the apparent Hill coefficient $n$ remains constant between unmodified and thio-modified variants, the free-energy difference is directly related to the ratio of the folding midpoints $\left[\mathrm{M}^{2+}\right]_{1 / 2}^{O}$ and $\left[\mathrm{M}^{2+}\right]_{1 / 2}^{S}$ :

$$
\Delta \Delta \mathrm{G}=-n R T \ln \left(\frac{\left[\mathrm{M}^{2+}\right]_{1 / 2}^{\mathrm{O}}}{\left[\mathrm{M}^{2+}\right]_{1 / 2}^{\mathrm{S}}}\right) .
$$

If folding of both the unmodified and thio-modified RNAs is measured in $\mathrm{Mg}^{2+}$ and $\mathrm{Mn}^{2+}$, and titrations in both metal ions happen to again yield the same Hill coefficient $n$, this framework gives

$$
\Delta \Delta \Delta \mathrm{G}=-n R T \ln \left[\frac{\left(\frac{\left[\mathrm{M}^{2+}\right]_{1 / 2}^{\mathrm{O}}}{\left[\mathrm{M}^{2+}\right]_{1 / 2}^{\mathrm{S}}}\right)_{\mathrm{Mg}^{2+}}}{\left(\frac{\left[\mathrm{M}^{2+}\right]_{1 / 2}^{\mathrm{O}}}{\left[\mathrm{M}^{2+}\right]_{1 / 2}^{\mathrm{S}}}\right)_{\mathrm{Mn}^{2+}}}\right] .
$$

In this scenario, describing the metal-ion rescue results in terms of "fold rescue" is equivalent to discussing the freeenergy differences $\Delta \Delta \Delta \mathrm{G}$, with a quantitative translation provided by Equation 4. Nevertheless, as discussed further below, two problems frequently complicate this description. First, fitted Hill coefficients often differ for destabilized variants or when different metal ions induce folding. Equations 3 and 4 are not applicable in these situations, and Equation 2 leads to free-energy estimates that depend on the choice of reference metal-ion concentration. Second, distinct, partially folded states are frequently observed at intermediate $\mathrm{M}^{2+}$ concentrations (see below, "Low salt comparisons"), so that a single midpoint and Hill coefficient are not sufficient to describe a folding titration. Instead, multiple folding transitions must be interrogated and characterized.

One approach for minimizing these problems and simplifying analyses is to saturate the ion atmosphere with a high concentration of monovalent cations, such that any associated divalent cations occupy specific metal-ion binding sites nearly exclusively, rather than the ion atmosphere (Bukhman and Draper 1997; Horton et al. 1998). This approach has been directly tested and validated with P4-P6 RNA, where structure mapping and direct ion counting assays showed a congruence of simple two-state folding with a Hill slope of 2 and binding of two $\mathrm{Mg}^{2+}$ ions (Scheme 2; Das et al. 2005b). We therefore first investigated P4-P6 folding and metal-ion rescue in a background of $2 \mathrm{M} \mathrm{NaCl}$. We then turned to more standard conditions of low monovalent salt concentration, such as were used in the prior metal-ion rescue study (Basu and Strobel 1999). We first present results in terms of "fold rescue," qualitatively comparing effects for substitution of inner- and outer-sphere ligands. To take into account observations of varying Hill coefficients (and later, additional intermediates), we developed general thermodynamic treatments that allow systematic estimation of free-energy differences for metalion-dependent folding events, and provide quantitative support for the specific conclusions herein.

\section{$\mathrm{Mg}^{2+}$ - and $\mathrm{Mn}^{2+}$-induced folding of P4-P6 in $2 \mathrm{M} \mathrm{NaCl}$}

The P4-P6 domain (Murphy and Cech 1993) consists of two sets of coaxially stacked helices-P4-P5-P6 and P5aP5b-joined by a hinge region (J5/5a) (Fig. 1A,B). Two interactions connect these helical stacks in the folded state: a tetraloop-receptor interaction between the loop of P5b and internal loops in P6 (J6a/b and J6b/a) and an A-minor interaction between an A-rich bulge within P5a and the P4

$$
\mathrm{I}_{\mathrm{TL}-\mathrm{TR}}+2 \mathrm{M}^{2+} \rightleftharpoons \mathrm{F} \cdot 2 \mathrm{M}^{2+}
$$

\section{SCHEME 2.}



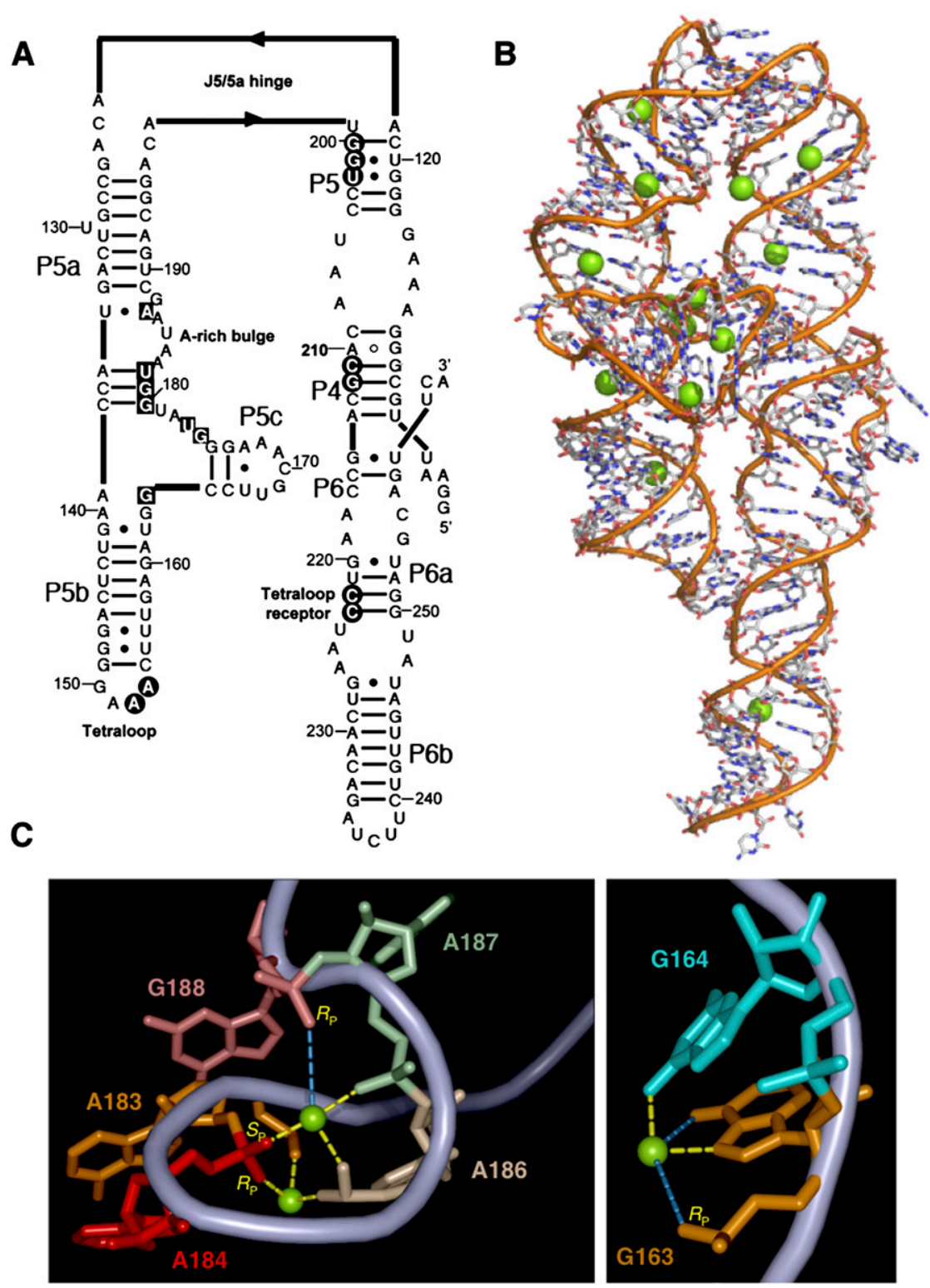

FIGURE 1. Structure of $\Delta$ C209 P4-P6 RNA. (A) Secondary structure of $\Delta$ C209 P4-P6. Nucleotides protected from hydroxyl radical cleavage in the folded state are shown as black circles (tertiary protections) or as black squares (subdomain protections). (B) Crystal structure of $\Delta \mathrm{C} 209$ P4-P6 (derived from PDB file 1HR2). Green spheres represent magnesium ions observed in the structure. (C) Detail of metal ion binding sites in $\Delta$ C209 P4-P6 relevant to this work. Within the A-rich bulge (left) and the trihelical junction (right), magnesium ions make several inner-sphere (yellow dashes) and outer-sphere (blue dashes) contacts to nucleobases and nonbridging phosphate oxygens. The specific phosphate oxygens modified in this work are labeled in yellow text.

helix. We refer to these connections as "tertiary interactions" herein. In our studies we have used $\Delta$ C209 P4-P6 RNA. The deletion of C209 thermostabilizes the folded RNA; the normally extruded A210 forms a noncanonical base pair with G111 within the P4 helix (Juneau and Cech 1999), but the structure is otherwise unchanged from wildtype P4-P6 (Juneau et al. 2001). We refer to this construct as P4-P6 or unmodified P4-P6 throughout for simplicity, unless noted otherwise.
Several $\mathrm{Mg}^{2+}$ ions are observed in the crystal structures of P4-P6 (Cate et al. 1996; Juneau et al. 2001). Within the A-rich bulge, two $\mathrm{Mg}^{2+}$ ions each make three inner-sphere contacts to nonbridging phosphate oxygen atoms contributed by A183, A184, A186, and A187 (Fig. 1C, left). In addition, the pro- $R_{\mathrm{P}}$ nonbridging oxygen of G188 lies within outer-sphere coordination distance of one of these metal ions. A third metal ion directly coordinates the N7 and $\mathrm{O} 6$ atoms of G163 and G164, respectively, and makes an apparent outer-sphere contact to the pro- $R_{\mathrm{P}}$ nonbridging oxygen of G163 (Fig. 1C, right). These metal ions bind within the P5abc subdomain, which can undergo divalent metal-ion-dependent folding in isolation (Murphy and Cech 1993; Wu and Tinoco 1998; Silverman et al. 1999; Zheng et al. 2001). Several other metal ions are observed in P4-P6 crystal structures, but are not addressed herein.

In $2 \mathrm{M} \mathrm{NaCl}$, wild type P4-P6 acquires nearly all native long-range tertiary contacts (Takamoto et al. 2004; Das et al. 2005b). The remaining tertiary interactions-those within P5abc and between the A-rich bulge (residues 182-188) and the $\mathrm{P} 4$ helix-are in the vicinity of the inner-sphere metal ions and form only upon addition of divalent metal ions (Fig. 2). Initial experiments showed that $\Delta$ C209 P4-P6 forms the same tertiary interactions in $2 \mathrm{M} \mathrm{NaCl}$, as reflected by protection from hydroxyl radical cleavage of nucleotides 152-153 (P5b tetraloop), 200-202 (J5/5a hinge), and 222-223 (tetraloop-receptor) (Fig. 1A; data not shown). This state is termed $\mathrm{I}_{\mathrm{TL}-\mathrm{TR}}$ herein. The addition of $\mathrm{Mg}^{2+}$ or $\mathrm{Mn}^{2+}$ induces protection of P5abc subdomain nucleotides 164, 176-177, $180-182$, and 187 , as well as nucleotides 211-212 (the A-rich bulge/P4 A-minor interaction), a transition we term $\mathrm{I}_{\mathrm{TL}-\mathrm{TR}}$-to-F (Scheme 2; Fig. 2). In $\mathrm{Mg}^{2+}$, these protections appear with a midpoint of $0.24 \pm 0.01 \mathrm{mM}$, whereas in $\mathrm{Mn}^{2+}$ the corresponding protections appear at a fourfold lower concentration $(0.06 \pm 0.01 \mathrm{mM})$, indicating significant $\mathrm{Mn}^{2+}$-specific stabilization (Fig. 3A; Table 1). Both in $\mathrm{Mg}^{2+}$ and $\mathrm{Mn}^{2+}$, transitions occur with a Hill coefficient of approximately two (e.g., $1.8 \pm 0.2$ for both $\mathrm{Mg}^{2+}$ and $\mathrm{Mn}^{2+}$ titrations monitored at nucleotide 


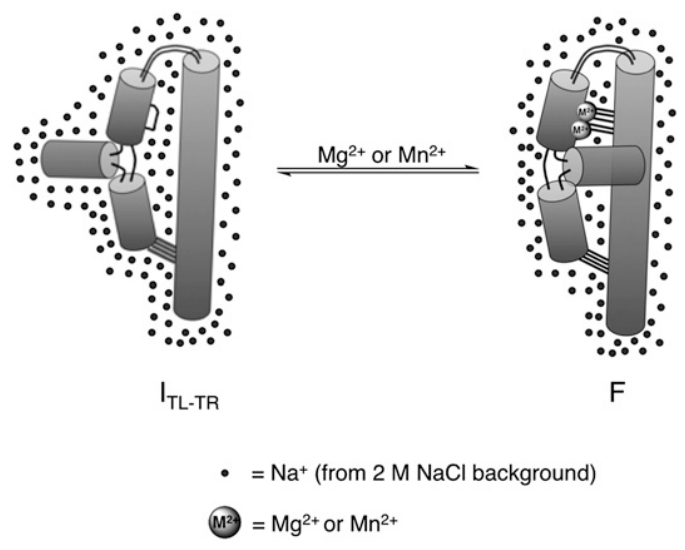

FIGURE 2. Model for equilibrium $\mathrm{Mg}^{2+}$ - or $\mathrm{Mn}^{2+}$-induced folding of unmodified $\mathrm{P} 4-\mathrm{P} 6$ in a background of $2 \mathrm{M} \mathrm{NaCl}$, which promotes the formation of a subset of long-range tertiary interactions. Two $\mathrm{Mg}^{2+}$ or $\mathrm{Mn}^{2+}$ ions bind within the A-rich bulge to form the final folded structure. (Adapted from Das et al. 2005b with permission from American Chemical Society (C) 2005.)

164; Table 1; Supplemental Table S1), consistent with prior work that demonstrated binding of two metal ions to induce formation of the fully folded state in $2 \mathrm{M} \mathrm{NaCl}$ (Das et al. 2005b; Travers et al. 2007).

The observation that $\mathrm{Mn}^{2+}$ aids folding of P4-P6 even in the absence of phosphorothioate substitutions raised the possibility that prior findings of "anomalous" rescue of outer-sphere metal-ion interactions arose from this enhanced overall stability and not from a specific ability of $\mathrm{Mn}^{2+}$ to rescue outer sphere interactions. We therefore revisited these crystallographic outer-sphere ligands with a thermodynamically rigorous approach, focusing on the pro- $R_{\mathrm{P}}$ nonbridging oxygen atoms of G188 or G163. Prior analog-interference analyses have shown that sulfur substitution at either of these sites disrupts folding in $2 \mathrm{mM}$ $\mathrm{Mg}^{2+}$ and low concentrations of monovalent cations, as measured by native gel electrophoresis (Cate et al. 1997; Basu and Strobel 1999). Inclusion of $0.3 \mathrm{mM} \mathrm{Mn}^{2+}$ with 1.7 $\mathrm{mM} \mathrm{Mg}^{2+}$ induced an apparent rescue of folding at both of these sites (Basu and Strobel 1999). This rescue by inclusion of a small amount of $\mathrm{Mn}^{2+}$ was taken as evidence for an ability of $\mathrm{Mn}^{2+}$ to rescue outer-sphere metal-ion interactions, a highly unexpected result as noted above. The single "rescuing" metal-ion mixture was chosen because it did not suppress folding interference of a nonmetal site phosphorothioate (A139 $R_{\mathrm{P}}$ PS) and several 2'-deoxy interference sites. The mixture therefore was thought to minimize any nonspecific stabilizing effects of $\mathrm{Mn}^{2+}$. However, no attempt was made to measure nonspecific stabilizing effects of $\mathrm{Mn}^{2+}$ on the folding of unmodified P4-P6, the comparison species for which nonspecific $\mathrm{Mn}^{2+}$ effects would have meaning in the experiment. In effect, the prior study used A139 $R_{\mathrm{P}}$ PS and the $2^{\prime}$-deoxy interferences as substitutes for unmodified $\mathrm{P} 4-\mathrm{P} 6$, whose folding behavior in $\mathrm{Mn}^{2+}$ was never assessed.
Hydroxyl radical footprinting for G188 $R_{\mathrm{P}}$ PS gave protections at a sevenfold higher $\mathrm{Mg}^{2+}$ midpoint (1.66 \pm $0.05 \mathrm{mM}$ ) relative to unmodified P4-P6 (Fig. 3B; Table 1). For G163 $R_{\mathrm{P}}$ PS, the protections appeared at a twofold higher $\mathrm{Mg}^{2+}$ midpoint $(0.46 \pm 0.06 \mathrm{mM})$ relative to unmodified P4-P6 (Fig. 3C; Table 1). These results indicate that sulfur substitution of either putative outer-sphere ligand destabilizes folding, and that increasing the $\mathrm{Mg}^{2+}$ concentration can overcome the effects of the substitution. Saturating $\mathrm{Mg}^{2+}$ induced the same protection patterns in G188 $R_{\mathrm{P}}$ PS and G163 $R_{\mathrm{P}}$ PS as for unmodified $\mathrm{P} 4-\mathrm{P} 6$, indicating that at the resolution of the assay, neither substitution changes the folded P4-P6 structure (data not shown).

The corresponding $\mathrm{Mn}^{2+}$ midpoints for the protections for G188 $R_{\mathrm{P}}$ PS and G163 $R_{\mathrm{P}}$ PS P4-P6 in $2 \mathrm{M} \mathrm{NaCl}$ were $0.32 \pm 0.01 \mathrm{mM}$ and $0.11 \pm 0.01 \mathrm{mM}$, respectively (Fig. 3B,C; Table 1). The two modifications increased the midpoint for folding in $\mathrm{Mn}^{2+}$ by fivefold and twofold, respectively, nearly the same effects as in $\mathrm{Mg}^{2+}$ (ratios of sevenfold and twofold, respectively) (Fig. 3B,C; Table 1). Thus, there is no specific $\mathrm{Mn}^{2+}$ rescue of the outer-sphere phosphorothioates under these conditions. Instead, compared with $\mathrm{Mg}^{2+}, \mathrm{Mn}^{2+}$ has a nonspecific and similar stabilizing effect for the unmodified RNA and its variants with outer-sphere phosphorothioates. This conclusion is rendered more quantitative and precise by taking into account lowered apparent Hill coefficients for the mutants (see Table 1) within the thermodynamic framework described in the next section. In particular, Model 1 and Scheme 3 below provide a physical explanation for the change in the apparent Hill coefficient for the variants under these conditions.

We next investigated whether $\mathrm{Mn}^{2+}$ could rescue folding of P4-P6 RNAs bearing phosphorothioate substitutions of inner-sphere $\mathrm{Mg}^{2+}$ ligands. We focused on $\mathrm{A} 184$, whose nonbridging oxygens make inner-sphere contacts to each of the A-rich bulge's metal ions in crystallographic models (Fig. 1C, left). Sulfur substitution of the pro- $R_{\mathrm{P}}$ oxygen of A184 interfered with P4-P6 folding using the aforementioned native gel assay (Cate et al. 1997; Basu and Strobel 1999). Neither $\mathrm{Mn}^{2+}$ nor other soft metal ions suppressed this folding interference under the single assay condition used previously (Basu and Strobel 1999). Sulfur substitution of the pro- $S_{\mathrm{P}}$ oxygen of $\mathrm{A} 184$ has not been reported. We constructed three P4-P6 RNAs with phosphorothioate substitutions of the pro- $R_{\mathrm{P}}$, pro- $S_{\mathrm{P}}$, or both (phosphorodithioate, $\mathrm{PS}_{2}$ ) nonbridging oxygens of A184 (Supplemental Fig. S1).

In $2 \mathrm{M} \mathrm{NaCl}$, the $\mathrm{Mg}^{2+}$ - and $\mathrm{Mn}^{2+}$-induced protection patterns for A184 $R_{\mathrm{P}}$ PS, A184 $S_{\mathrm{P}} \mathrm{PS}$, and $\mathrm{A} 184 \mathrm{PS}_{2}$ RNAs closely resemble those of unmodified P4-P6 (data not shown). This similarity suggests that the folded structures of these inner-sphere mutants closely resemble the structure of unmodified P4-P6 RNA. However, the phosphorothioate substitution of either or both of the nonbridging 

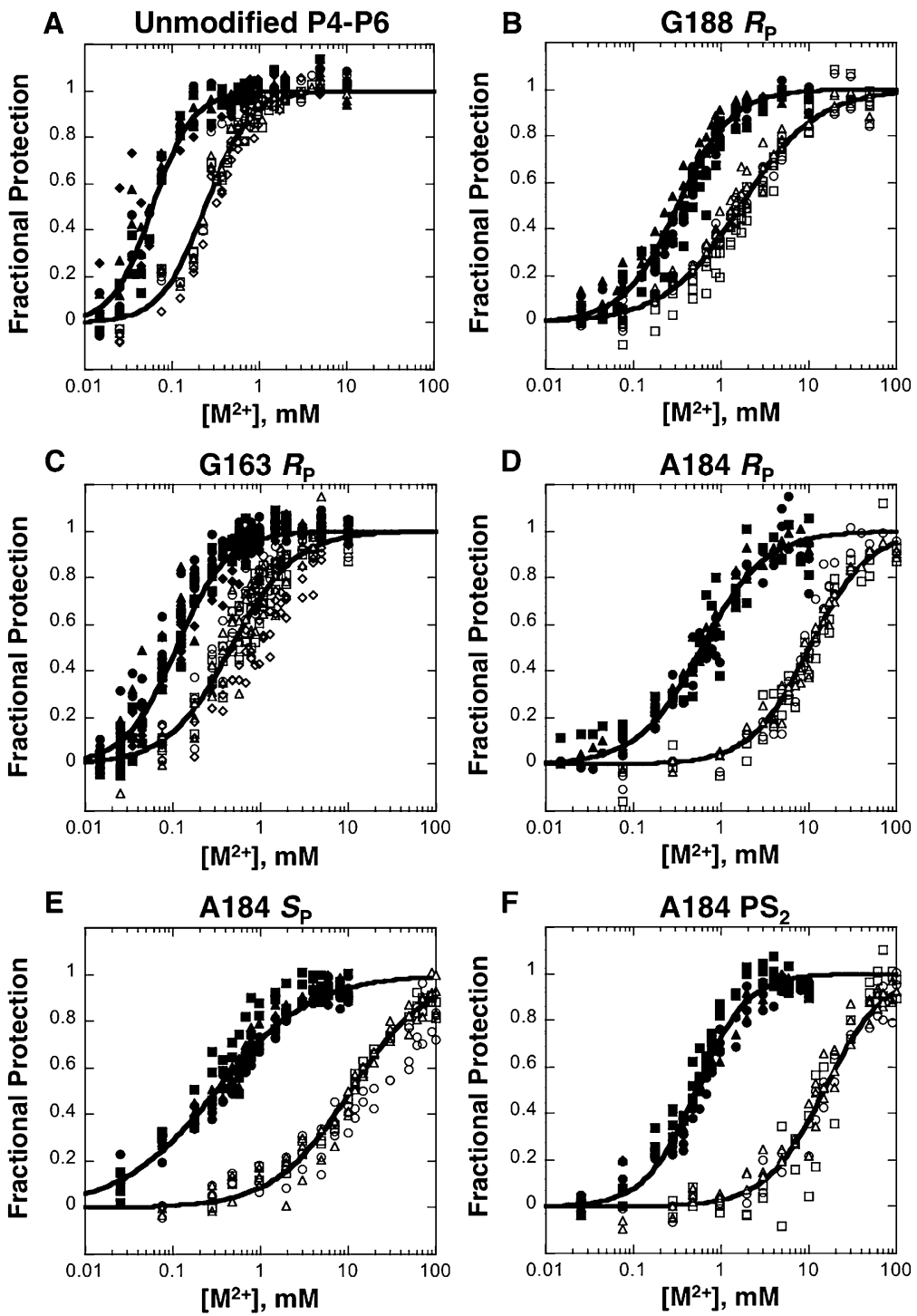

FIGURE 3. Equilibrium $\mathrm{Mg}^{2+}$ - and $\mathrm{Mn}^{2+}$-induced folding of unmodified P4-P6 $(A)$ and phosphorothioate-substituted variants $(B-F)$ in a background of $2 \mathrm{M} \mathrm{NaCl}$ (with $50 \mathrm{mM} \mathrm{Na}$ MOPS at $\mathrm{pH} 7) . \mathrm{Mg}^{2+}$ data points are shown as open symbols and $\mathrm{Mn}^{2+}$ data points are shown as closed symbols. Values of the fractional protection from hydroxyl radical cleavage derived from two to four independent experiments for subdomain nucleotides 164 (triangles), 176-177 (circles), 180-182 (squares), and 187 (diamonds) were averaged according to the procedure outlined in the Materials and Methods and Supplemental Material. The resulting values were fit to the Hill equation to yield curves whose midpoints and Hill coefficients reflect the appearance of protections over all of the protected nucleotides simultaneously. Data for nucleotide 187 are not included for certain variants due to nonspecific degradation of the phosphorothioate linkage, which interfered with the protection signal at this site.

oxygens of A184 destabilized $\mathrm{Mg}^{2+}$-induced P4-P6 folding dramatically compared with unmodified P4-P6, with the $\mathrm{Mg}^{2+}$ midpoints associated with the appearance of protections occurring at 43-, 44-, and 63-fold higher $\mathrm{Mg}^{2+}$ concentrations than unmodified P4-P6 (Fig. 3A,D-F; Table 1). In $\mathrm{Mn}^{2+}$, the folding midpoints for the three innersphere constructs increase by $10-$, five-, and ninefold relative to the unmodified RNA (Fig. 3A,D-F; Table 1). The ratios of these $\mathrm{Mg}^{2+}$ and $\mathrm{Mn}^{2+}$ midpoints give apparent fold rescue values of 4,9 , and 7 , respectively, much greater than the values of near unity obtained for the outer-sphere substitutions (Fig. 4A).

These results suggest that $\mathrm{Mn}^{2+}$ specifically rescues folding of A184 $R_{\mathrm{P}} \mathrm{PS}$, $\mathrm{A} 184 S_{\mathrm{P}} \mathrm{PS}$, and $\mathrm{A} 184 \mathrm{PS}_{2}$ relative to unmodified P4-P6, a result that is typically taken as evidence for innersphere coordination between $\mathrm{Mn}^{2+}$ and the phosphorothioate, and is consistent with the crystal structure of P4-P6 with $\mathrm{Mg}^{2+}$ and unsubstituted phosphates (Fig. 1; Cate et al. 1996; Juneau et al. 2001). These results further suggest that the two divalent metal ions that bind cooperatively with P4-P6 folding in the $2 \mathrm{M} \mathrm{NaCl}$ background are the metal ions that make inner-sphere interactions with the phosphoryl oxygen atoms of residue A184. Nevertheless, the apparent Hill coefficients are different for different variants (Table 1; Supplemental Fig. S2); thus, as noted above, "fold-rescue" values do not report directly on $\Delta \Delta \Delta \mathrm{G}$ (i.e., Equations 3 and 4 are invalid) and, at best, give a qualitative summary of the results. To make basic conclusions about the energetic significance of these effects, a thermodynamic framework for computing the free-energy differences of metal-ion rescue is necessary. Such a framework is discussed next.

\section{Thermodynamic models consistent with the rescue data}

Estimating free-energy differences from the $\mathrm{Mg}^{2+}$ and $\mathrm{Mn}^{2+}$ titration data for the P4-P6 RNA and its variants requires extending the "standard" thermodynamic framework in Equations 1-4, which assumes that Hill coefficients for different RNAs are constant at different divalent metal-ion concentrations. In particular, the fitted Hill coefficients for the thio-modified variants are systematically lower than the values of $\sim 2$ for the unmodified RNA (Table 1; Supplemental Table S1; Supplemental Fig. S2) and, indeed, decrease to values near 1 for the more destabilized variants (Table 1; Supplemental Table S1). We therefore sought simple extensions of the thermodynamic framework (Weiss 1997; Garcia et al. 2011) that model changing Hill slopes, while still permitting extraction of welldefined $\Delta \Delta \mathrm{G}$ and $\Delta \Delta \Delta \mathrm{G}$ values for evaluating metal-ion 
TABLE 1. $\mathrm{Mg}^{2+}$ - and $\mathrm{Mn}^{2+}$-dependent folding of P4-P6 in $2 \mathrm{M} \mathrm{NaCl}$

Weighted average across residues 164-187 (P5abc subdomain)

\begin{tabular}{lccccc}
\cline { 3 - 7 } Construct & Ligand type & {$\left[\mathrm{Mg}^{2+}\right]_{1 / 2}(\mathrm{mM})$} & $n_{\text {Hill }}$ & {$\left[\mathrm{Mn}^{2+}\right]_{1 / 2}(\mathrm{mM})$} & $n_{\text {Hill }}$ \\
\hline Unmodified & & $0.24 \pm 0.01$ & $1.7 \pm 0.1$ & $0.06 \pm 0.01$ & $1.9 \pm 0.1$ \\
G188 $R_{\mathrm{P}}$ & OS & $1.66 \pm 0.05$ & $1.0 \pm 0.1$ & $0.32 \pm 0.01$ & $1.4 \pm 0.1$ \\
$\mathrm{G} 163 R_{\mathrm{P}}$ & OS & $0.46 \pm 0.06$ & $1.2 \pm 0.1$ & $0.11 \pm 0.01$ & $1.5 \pm 0.1$ \\
$\mathrm{~A} 184 R_{\mathrm{P}}$ & $\mathrm{IS}$ & $10.2 \pm 0.6$ & $1.3 \pm 0.1$ & $0.60 \pm 0.05$ & $1.2 \pm 0.1$ \\
$\mathrm{~A} 184 S_{\mathrm{P}}$ & $\mathrm{IS}$ & $10.6 \pm 0.3$ & $1.0 \pm 0.1$ & $0.31 \pm 0.04$ & $0.8 \pm 0.1$ \\
$\mathrm{~A} 184 \mathrm{PS}_{2}$ & $\mathrm{IS}$ & $15 \pm 2$ & $1.3 \pm 0.1$ & $0.52 \pm 0.02$ & $1.5 \pm 0.1$ \\
\hline
\end{tabular}

thio modifications. We also assumed that the first equilibrium-binding of an "extra" metal ion to $\mathrm{I}_{\mathrm{TL}-\mathrm{TR}}$ with equilibrium constant $\mathrm{K}_{1}$-was the same for all mutants, as would be expected if this metal ion was diffusely associated with the RNA and if all variants had similar structural ensembles in the metal core-free $\mathrm{I}_{\mathrm{TL}-\mathrm{TR}}$ state. Equations for fraction folded, free energies, and $\mathrm{M}^{2+}$-dependent Hill coefficients are given in the Supplemental Material. The model predicts that if a variant rescue. We explored two such models and found them to give numerical free-energy differences for the data herein that were indistinguishable within experimental error.

Model 1. Two site-bound metal ions derived from solution or from the atmosphere

The data herein and from previous work are well fit by a model in which $\mathrm{I}_{\mathrm{TL}-\mathrm{TR}}$-to-F folding of unmodified P4-P6 is associated with the specific site binding of two divalent metal ions brought in from solution (Scheme 2). Due to the large excess of $\mathrm{Na}^{+}$saturating the atmosphere (cf. solution concentrations of $2 \mathrm{M} \mathrm{NaCl}$ with submillimolar $\mathrm{MgCl}_{2}$ or $\mathrm{MnCl}_{2}$ ), the number of "atmospheric" divalent metal ions is assumed to be either negligible or similar in the $\mathrm{I}_{\mathrm{TL}-\mathrm{TR}}$ and $\mathrm{F}$ states and, indeed, the number of these background ions was verified to be one or less by direct ion counting (Das et al. 2005b). Scheme 2 does not show these diffusely bound divalent metal ions, sodium ions, or chloride ions, as they are negligible in the thermodynamic formulas describing the titration (Equations 1 and 2, with $n=2$ ). However, for the destabilized thio-modified variants herein, higher concentrations of divalent ions are required to probe the $\mathrm{I}_{\mathrm{TL}-\mathrm{TR}}$-to-F transition, raising the possibility that some atmospheric divalent metal ions might be present in $\mathrm{I}_{\mathrm{TL}-\mathrm{TR}}$ under these conditions and that these metal ions might enter the metalion core upon folding to F. Because we assumed that F contains a maximum of two site-bound ions, we considered the possibility that $\mathrm{I}_{\mathrm{TL}-\mathrm{TR}}$ preassociates with a single metal ion to form $\mathrm{I}_{\mathrm{TL}-\mathrm{TR}} \bullet \mathrm{M}^{2+}$ according to a separate equilibrium constant, $\mathrm{K}_{1}$ (Scheme 3 ). We also considered a model with two metal ions preassociated with $\mathrm{I}_{\mathrm{TL}-\mathrm{TR}}$ to form an additional species $\left(\mathrm{I}_{\mathrm{TL}-\mathrm{TR}} \cdot 2 \mathrm{M}^{2+}\right)$; a significant fraction of such a species would lead to an admixture of $\mathrm{I}_{\mathrm{TL}-\mathrm{TR}}$ and $\mathrm{F}$ at high divalent metal-ion concentrations. As we observe hydroxyl radical reactivities consistent with complete folding of all the RNAs herein, we do not include such a species. According to Scheme 3, folding to $\mathrm{F} \cdot 2 \mathrm{M}^{2+}$ occurs either from the $\mathrm{I}_{\mathrm{TL}-\mathrm{TR}}$ species via $\mathrm{K}_{2}$, or from $\mathrm{I}_{\mathrm{TL}-\mathrm{TR}} \bullet \mathrm{M}^{2+}$.

To apply Scheme 3 to the metal-ion rescue experiments, we assumed that the second equilibrium, which involves folding from $\mathrm{I}_{\mathrm{TL}-\mathrm{TR}} \bullet \mathrm{M}^{2+}$ to form $\mathrm{F} \cdot 2 \mathrm{M}^{2+}$ via binding of a second divalent metal ion, was perturbed by the assayed folds with a midpoint $\left[\mathrm{M}^{2+}\right]_{1 / 2}$, its apparent Hill coefficient is

$$
n=2-\left(\frac{\frac{\left[\mathrm{M}^{2+}\right]}{\mathrm{K}_{1}}}{1+\frac{\left[\mathrm{M}^{2+}\right]}{\mathrm{K}_{1}}}\right) \text {. }
$$

This equation gives a Hill coefficient of 2 for stable variants, monotonically decreasing to 1 for destabilized variants, resulting from preassociation of a single metal ion with $\mathrm{I}_{\mathrm{TL}-\mathrm{TR}}$ at higher divalent metal-ion concentrations as prescribed by the model. This model accounts for the entire $\mathrm{Mg}^{2+}$ and $\mathrm{Mn}^{2+}$ data sets of unmodified P4-P6 and the five variants (Fig. 5, solid lines), with $\mathrm{K}_{1}$ values of $0.26 \pm 0.16 \mathrm{mM}\left(\mathrm{Mg}^{2+}\right)$ and $0.13 \pm 0.08 \mathrm{mM}\left(\mathrm{Mn}^{2+}\right)$. This global fit then permits quantitative evaluation of the free-energy differences and metal-ion rescue for each P4-P6 thio substitution (Table 2).

For the putative outer-sphere ligand modifications, the $\mathrm{Mg}^{2+}$-dependent folding transition $\mathrm{I}_{\mathrm{TL}-\mathrm{TR}}$-to-F was destabilized by $\Delta \Delta \mathrm{G}$ values of $1.49 \pm 0.15 \mathrm{kcal} / \mathrm{mol}$ and $0.55 \pm 0.13$ $\mathrm{kcal} / \mathrm{mol}$ for G188 $R_{\mathrm{P}}$ PS and G163 $R_{\mathrm{P}}$ PS, respectively (Table 2). When folded in $\mathrm{Mn}^{2+}$, the destabilization $\Delta \Delta \mathrm{G}$ values for these two variants were $1.47 \pm 0.23 \mathrm{kcal} / \mathrm{mol}$ and $0.58 \pm$ $0.20 \mathrm{kcal} / \mathrm{mol}$, indistinguishable from the $\mathrm{Mg}^{2+}$ values, given experimental error. The metal-ion rescue free-energy values $\Delta \Delta \Delta \mathrm{G}$ were obtained by subtracting the $\mathrm{Mg}^{2+}$ and $\mathrm{Mn}^{2+}$ $\Delta \Delta \mathrm{G}$ values and gave $0.02 \pm 0.28 \mathrm{kcal} / \mathrm{mol}$ and $-0.02 \pm 0.24$ $\mathrm{kcal} / \mathrm{mol}$ for G188 $R_{\mathrm{P}}$ PS and G163 $R_{\mathrm{P}}$ PS, respectively. Both values were indistinguishable from zero $(P=0.5)$. This analysis indicates that substituting phosphorothioates for these crystallographically observed outer-sphere ligands in the P4-P6 system results in negligible metal-ion rescue.

For the putative inner-sphere ligand modifications A184 $R_{\mathrm{P}}$ PS, A184 $S_{\mathrm{P}} \mathrm{PS}$, and $\mathrm{A} 184 \mathrm{PS}_{2}$, this framework gave

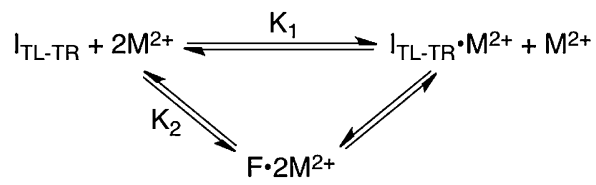

SCHEME 3. 
A

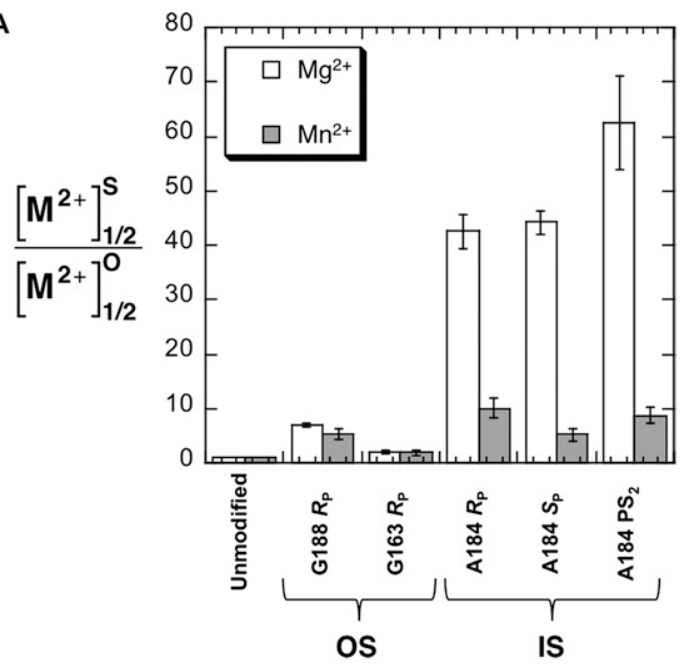

B

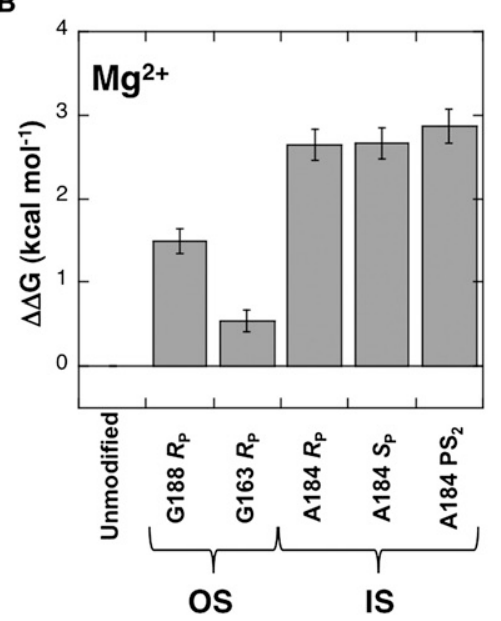

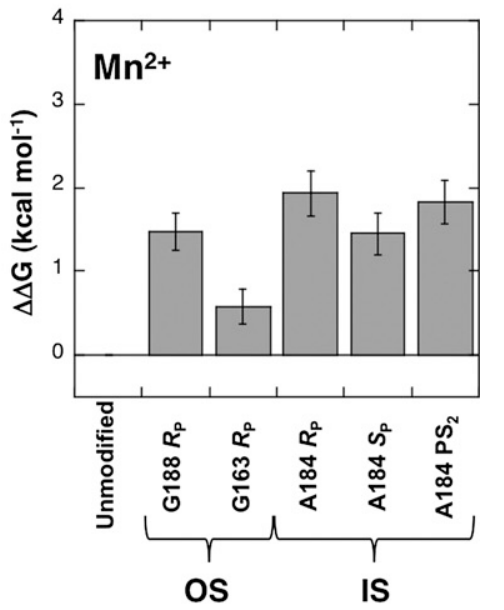

C

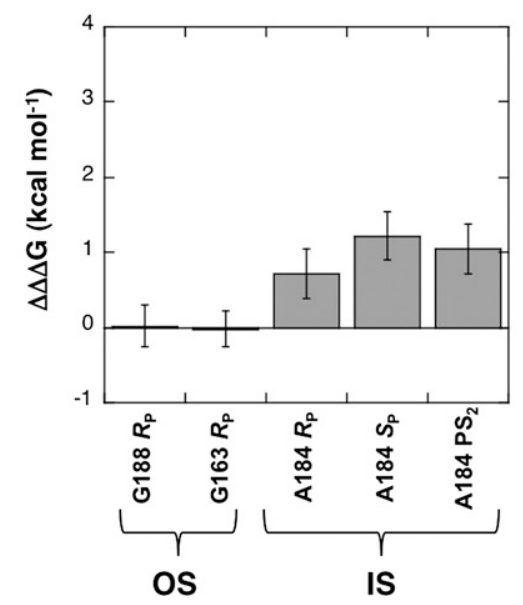

FIGURE 4. (A) Divalent metal-ion midpoint ratios of P4-P6 variants folded in either $\mathrm{Mg}^{2+}$ or in $\mathrm{Mn}^{2+}$ in a background of $2 \mathrm{M} \mathrm{NaCl}$ (OS: outer-sphere metal-ion ligand; IS: inner-sphere metal-ion ligand). (B) Calculated $\Delta \Delta \mathrm{G}$ values (relative to unmodified P4-P6) associated with $\mathrm{Mg}^{2+}$-induced (left) and $\mathrm{Mn}^{2+}$-induced (right) folding of P4-P6 phosphorothioate variants with respect to unmodified P4-P6. The values were calculated according to a thermodynamic framework in which two site-bound metal ions, derived from solution or from the ion atmosphere, bind within the metal-ion core (Model 1, Supplemental Material). (C) Calculated $\Delta \Delta \Delta \mathrm{G}$ values associated with $\mathrm{Mg}^{2+}$ - vs. $\mathrm{Mn}^{2+}$-induced folding of phosphorothioate-subsituted $\mathrm{P} 4-\mathrm{P} 6$ variants in a background of $2 \mathrm{M} \mathrm{NaCl}$.

$\Delta \Delta \mathrm{G}$ values of $2.64 \pm 0.19 \mathrm{kcal} / \mathrm{mol}$, $2.66 \pm 0.19 \mathrm{kcal} / \mathrm{mol}$, and $2.87 \pm 0.21$ $\mathrm{kcal} / \mathrm{mol}$ for A184 $R_{\mathrm{P}} \mathrm{PS}, \mathrm{A} 184 S_{\mathrm{P}} \mathrm{PS}$, and $\mathrm{A} 184 \mathrm{PS}_{2}$, respectively, for the folding transition $\mathrm{I}_{\mathrm{TL}-\mathrm{TR}}$-to-F induced by $\mathrm{Mg}^{2+}$ (Table 2). In contrast to the outer-sphere ligand experiments above, the $\Delta \Delta \mathrm{G}$ values for folding in $\mathrm{Mn}^{2+}$ were lower: $1.93 \pm 0.27,1.45 \pm 0.25$, and $1.83 \pm 0.26 \mathrm{kcal} / \mathrm{mol}$. Thus, the results suggest metal-ion rescue, with rescue free-energy values of $\Delta \Delta \Delta \mathrm{G}$ of $0.71 \pm 0.33 \mathrm{kcal} / \mathrm{mol}, 1.22 \pm 0.32 \mathrm{kcal} /$ $\mathrm{mol}$, and $1.04 \pm 0.33 \mathrm{kcal} / \mathrm{mol}$ for A184 $R_{\mathrm{P}}$ PS, A184 $S_{\mathrm{P}} \mathrm{PS}$, and A184 $\mathrm{PS}_{2}$, respectively. The results give strong evidence for nonzero metal-ion rescue for both A184 nonbridging oxygens ( $P$ $=0.02, P=7 \times 10^{-5}$, and $P=8 \times 10^{-4}$ for A184 $R_{\mathrm{P}}$ PS, A184 $S_{\mathrm{P}}$ PS, and A184 $\mathrm{PS}_{2}$, respectively), consistent with their observation as inner-sphere metal-ion ligands in the crystallographic analysis of P4-P6. Figure 4B shows the free energy differences $(\Delta \Delta G)$ for folding in both $\mathrm{Mg}^{2+}$ and $\mathrm{Mn}^{2+}$ in graphic form, while Figure $4 \mathrm{C}$ shows the rescue factors $(\Delta \Delta \Delta G)$ associated with each phosphorothioate construct.

\section{Model 2. Linear expansion of the apparent} Hill coefficient

Model 1 posits a functional form for how the free-energy difference $\Delta G$ for an RNA conformational transition varies with background divalent metal-ion concentration and assumes that each RNA modification perturbs this relationship by some constant $\Delta \Delta \mathrm{G}$. However, the model makes use of the special conditions of the experiment (high background sodium ion concentration) and assumptions specific to the P4-P6 metal core transition $\left(\mathrm{I}_{\mathrm{TL}-\mathrm{TR}}-\right.$ to- $\left.\mathrm{F}\right)$ to derive the relevant thermodynamic relations. To support the above analysis and to enable analysis under different monovalent ion background conditions (see below), we also explored a framework in which the expression for the free energy was assumed to take a more general form, and in which the data on the unmodified and thio-modified RNA were used to carry out a local mathematical expansion of 
A

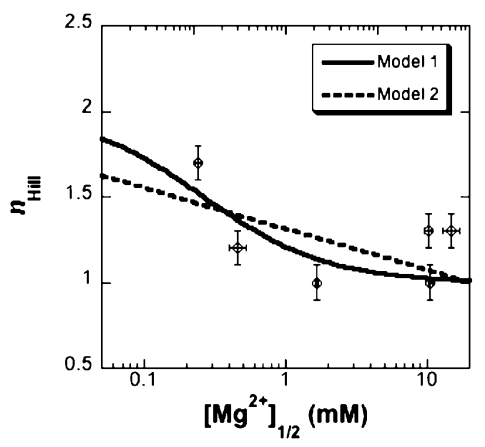

B

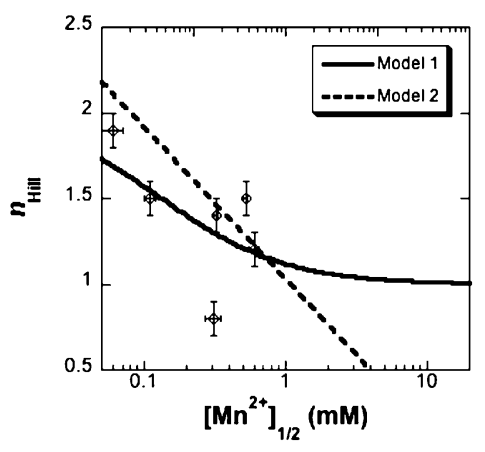

FIGURE 5. Curves describing the variation of the Hill coefficient $\left(n_{\text {Hill }}\right)$ with the divalent metal-ion folding midpoint according to models 1 (solid lines; see equation 5 ) and 2 (dashed lines; see equation 6) for folding of P4-P6 variants in $\mathrm{Mg}^{2+}(A)$ and in $\mathrm{Mn}^{2+}(B)$ in a background of $2 \mathrm{M} \mathrm{NaCl}$. The data points are the experimentally estimated values of $n_{\mathrm{Hill}}$ and $\left[\mathrm{M}^{2+}\right]_{1 / 2}$ for each individual RNA construct (Table 1).

the free energy as a function of metal-ion concentration. This framework has been applied previously to analyze the thermostabilization of a signal recognition particle RNA motif by substitutions predicted by the Rosetta design algorithm (Das et al. 2010).

Explicitly, we carried out the mathematical expansion on the apparent Hill coefficient function $n\left(\left[\mathrm{M}^{2+}\right]\right)$, which is proportional to the derivative of $\Delta G\left(\left[M^{2+}\right]\right)$ with respect to $\ln \left[\mathrm{M}^{2+}\right]$ (see Supplemental Material). This expansion does not require assumptions of high background monovalent ion concentrations or discreteness of the metal-ion binding sites, and thus is applicable as described below to conformational transitions that occur under low monovalent salt concentrations, which are more commonly encountered. We assumed that $n$ varies smoothly with $\left[\mathrm{M}^{2+}\right]$, as it does for computational models or direct measurements of ion atmospheres around fixed or changing RNA conformational ensembles (Manning 1977a,b; Anderson and Record 1990; Bai et al. 2007; Leipply and Draper 2010). We then confirmed that a simple linear expansion fits the observed apparent Hill coefficients herein (Fig. 5, dashed lines):

$$
n\left(\left[\mathrm{M}^{2+}\right]\right)=n_{0}+\alpha_{n} \ln \left[\frac{\left[\mathrm{M}^{2+}\right]}{\left(\left[\mathrm{M}^{2+}\right]_{1 / 2}\right)_{0}}\right] \text {. }
$$

Here, $n_{0}$, the apparent Hill coefficient of the unmodified RNA near its folding midpoint, and the coefficient $\alpha_{n}$ are fitted parameters, and $\left(\left[\mathrm{M}^{2+}\right]_{1 / 2}\right)$ is the folding midpoint of the unmodified construct. Note that the values of the fitted parameters depend on the different folding midpoints and Hill coefficients of each individual RNA variant (the data points in Fig. 5). The model therefore makes no assumptions about the values of the Hill coefficients, which retain their experimentally determined values.

The corresponding equations for free-energy differences (derived in the Supplemental Material) gave $\Delta \Delta \mathrm{G}$ values for all phosphorothioate modifications in both $\mathrm{Mg}^{2+}$ and $\mathrm{Mn}^{2+}$ that were within error of the values computed using Model 1 above (Table 2). In particular, the final metal-ion rescue values $\Delta \Delta \Delta \mathrm{G}$ were calculated to be $0.37 \pm 0.35 \mathrm{kcal} /$ $\mathrm{mol}(P=0.1), 0.06 \pm 0.29 \mathrm{kcal} / \mathrm{mol}(P=0.4), 1.34 \pm 0.61$ $\mathrm{kcal} / \mathrm{mol}(P=0.01), 1.72 \pm 0.58 \mathrm{kcal} / \mathrm{mol}(P=0.002)$, and $1.68 \pm 0.66 \mathrm{kcal} / \mathrm{mol}(P=0.005)$ for the modifications G188 $R_{\mathrm{P}}$ PS, G163 $R_{\mathrm{P}}$ PS, A184 $R_{\mathrm{P}}$ PS, A184 $S_{\mathrm{P}}$ PS, and A184 $\mathrm{PS}_{2}$, respectively. These values are indistinguishable within experimental error from those obtained using Model 1 above, and further support the conclusion that metal-ion rescue is negligible for outer-sphere sites, but significant for inner-sphere ligands.

\section{Testing rescue of P4-P6 folding in low background $\mathrm{Na}^{+}$concentration}

The above experiments carried out in $2 \mathrm{M} \mathrm{NaCl}$ support the conceptual underpinnings of metal-ion rescue experi-
TABLE 2. Folding free energy differences of unmodified vs. phosphorothioate-substituted $\mathrm{P} 4-\mathrm{P} 6$ in $2 \mathrm{M} \mathrm{NaCl}$

\begin{tabular}{|c|c|c|c|c|c|}
\hline \multirow[b]{2}{*}{ Construct } & \multirow[b]{2}{*}{ Ligand type } & \multirow[b]{2}{*}{ Model } & \multicolumn{2}{|c|}{$\Delta \Delta \mathrm{G}\left(\mathrm{kcal} \mathrm{mol}^{-1}\right)$} & \multirow[b]{2}{*}{$\Delta \Delta \Delta \mathrm{G}\left(\mathrm{kcal} \mathrm{mol}^{-1}\right.$} \\
\hline & & & $\mathrm{Mg}^{2+}$ & $\mathrm{Mn}^{2+}$ & \\
\hline \multirow[t]{2}{*}{$\mathrm{G} 188 R_{\mathrm{P}}$} & OS & 1 & $1.49 \pm 0.15$ & $1.47 \pm 0.23$ & $0.02 \pm 0.28$ \\
\hline & & 2 & $1.54 \pm 0.23$ & $1.17 \pm 0.27$ & $0.37 \pm 0.35$ \\
\hline \multirow[t]{2}{*}{$\mathrm{G} 163 R_{\mathrm{P}}$} & OS & 1 & $0.55 \pm 0.13$ & $0.58 \pm 0.20$ & $-0.02 \pm 0.24$ \\
\hline & & 2 & $0.53 \pm 0.13$ & $0.47 \pm 0.26$ & $0.06 \pm 0.29$ \\
\hline \multirow[t]{2}{*}{$\mathrm{A} 184 R_{\mathrm{P}}$} & IS & 1 & $2.64 \pm 0.19$ & $1.93 \pm 0.27$ & $0.71 \pm 0.33$ \\
\hline & & 2 & $2.85 \pm 0.50$ & $1.50 \pm 0.35$ & $1.34 \pm 0.61$ \\
\hline \multirow[t]{2}{*}{$\mathrm{A} 184 S_{\mathrm{P}}$} & IS & 1 & $2.66 \pm 0.19$ & $1.45 \pm 0.25$ & $1.22 \pm 0.32$ \\
\hline & & 2 & $2.87 \pm 0.51$ & $1.15 \pm 0.28$ & $1.72 \pm 0.58$ \\
\hline \multirow[t]{2}{*}{ A184 $\mathrm{PS}_{2}$} & IS & 1 & $2.87 \pm 0.21$ & $1.83 \pm 0.26$ & $1.04 \pm 0.33$ \\
\hline & & 2 & $3.11 \pm 0.57$ & $1.43 \pm 0.32$ & $1.68 \pm 0.66$ \\
\hline
\end{tabular}

Model 1: Two site-bound metal ions derived from solution or from the atmosphere. Model 2: Linear expansion of the apparent Hill coefficient. 
ments and indicate that, with proper thermodynamic comparisons, the approach can specifically identify site-bound metal ions within folded RNAs. To more directly compare these results with those obtained by Basu and Strobel (1999), to reveal another complexity in thermodynamic analyses, and to demonstrate how this complexity can be identified and addressed, we have carried out hydroxyl radical footprinting of the constructs described above in low background $\mathrm{Na}^{+}$concentration. We first describe the results in the absence of phosphorothioate substitutions, as these results reveal a critical new feature in the P4-P6 folding pathway.

$\mathrm{Mg}^{2+}$ - and $\mathrm{Mn}^{2+}$-induced folding of unmodified P4-P6 in low background $\mathrm{Na}^{+}$concentration

For P4-P6 folding in low-background monovalent cation concentration, in contrast to the behavior in $2 \mathrm{M} \mathrm{NaCl}$, the RNA initially lacks all of the tertiary interactions, so that extensive three-dimensional structure forms as $\mathrm{Mg}^{2+}$ or $\mathrm{Mn}^{2+}$ is added. Under these conditions, $\mathrm{P} 4-\mathrm{P} 6$ folds in $\mathrm{Mg}^{2+}$ via an apparent single cooperative transition (U-to-F) (Fig. $6 \mathrm{~A}$, left). All of the hydroxyl radical protections arise over a narrow $\mathrm{Mg}^{2+}$ concentration range, with an average midpoint and apparent Hill coefficient of $0.42 \pm 0.01 \mathrm{mM}$ and $4.2 \pm 0.1$, respectively (Fig. $6 \mathrm{~B}$, left; Table $3 \mathrm{~A}$ ). These values agree with those obtained for P4-P6 folding in low background monovalent cation concentration monitored by native gel electrophoresis $\left(\left[\mathrm{Mg}^{2+}\right]_{1 / 2}=0.46 \mathrm{mM}, n_{\text {Hill }} \sim 4\right)$ (Juneau et al. 2001; Schwans et al. 2003), which monitors global molecular compaction.

In contrast, $\mathrm{P} 4-\mathrm{P} 6$ folds via two transitions when $\mathrm{Mn}^{2+}$ is used as the divalent metal ion. A subset of the protections (152-153 and 200-202) appears at a slightly lower midpoint than in $\mathrm{Mg}^{2+}$, but protections of other residues (176177 and 180-182) occur at a 10-fold lower $\mathrm{Mn}^{2+}$ concentration (Fig. 6B, right; Table 3B). The residues that are protected at the lower $\mathrm{Mn}^{2+}$ concentration (closed squares) correspond to a previously identified folding subdomain, P5abc, which can adopt structure independent of the overall P4-P6 structure (Murphy and Cech 1993; Wu and Tinoco 1998; Silverman et al. 1999; Zheng et al. 2001). Thus, the first protections that appear with increasing $\mathrm{Mn}^{2+}$ concentration correspond to a previously unseen $\mathrm{U}-\mathrm{to}-\mathrm{I}_{\mathrm{P} 5 \mathrm{abc}}$ transition. The protections that arise at higher $\mathrm{Mn}^{2+}$ concentrations correspond to formation of the tertiary interactions between the two sets of coaxially stacked helices in the folded P4-P6 structure ( $\mathrm{I}_{\mathrm{P} 5 \mathrm{abc}}$-to-F) (Fig. 6B, closed circles; Fig. 1A,B). This three-state, two-transition folding model shown in the right panel of Figure 6A is supported by results with a P4-P6 mutant in which $\mathrm{J} / 5 \mathrm{a}$ is base paired to prevent formation of the overall tertiary structure. This mutant gives P5abc folding at low $\mathrm{Mn}^{2+}$ concentration as observed within the context of unmodified P4-P6, but requires considerably higher $\mathrm{Mg}^{2+}$ concentrations than unmodified P4-P6 to support acquisition of the final tertiary structure (Murphy and Cech 1994; Wu and Tinoco 1998; data not shown). The prior work using gel electrophoretic measurements (Basu and Strobel 1999; Silverman and Cech 1999; JK Frederiksen and $\mathrm{JH}$ Piccirilli, unpubl.) did not detect the U-to- $\mathrm{I}_{\mathrm{P} 5 \mathrm{abc}}$ transition, possibly because the structural change is too subtle to be detected at the resolution of a gel mobility assay.

Thus, in $20 \mathrm{mM} \mathrm{Na}^{+}$, acquisition of the final tertiary structure requires similar concentrations of $\mathrm{Mg}^{2+}$ and $\mathrm{Mn}^{2+}$, but the underlying process or folding mechanism is distinct, with $\mathrm{Mn}^{2+}$ promoting formation of a predominant folding intermediate that contains the two identified metal-ion binding sites (Fig. 6A, right). This difference has profound consequences. Whereas modifications that significantly weaken $\mathrm{Mg}^{2+}$ affinity for these binding sites would result in an increased $\left[\mathrm{Mg}^{2+}\right]_{1 / 2}$ for overall tertiary folding, the same modification in $\mathrm{Mn}^{2+}$ might have no influence on the $\left[\mathrm{Mn}^{2+}\right]_{1 / 2}$ for overall tertiary folding. In other words, a modification that increases the $\left[\mathrm{Mn}^{2+}\right]_{1 / 2}$ for formation of the subdomain (which contains the metal-ion binding sites) by $\sim 10$-fold would still allow metal-ion binding and subdomain formation at a $\mathrm{Mn}^{2+}$ concentration below that required for formation of the overall tertiary structure (Fig. 6B, open vs. closed symbols) so that no shift in $\left[\mathrm{Mn}^{2+}\right]_{1 / 2}$ for the overall tertiary structure formation would be observed.

Because of the different folding pathways, any mutation or modification that uniformly perturbed the $\left[\mathrm{M}^{2+}\right]_{1 / 2}$ for the single folding transition in $\mathrm{Mg}^{2+}$ and for subdomain formation in $\mathrm{Mn}^{2+}$, such as modification of an outer-sphere ligand, would give apparent rescue in gel mobility measurements, which monitor only overall tertiary structure formation (i.e., the ratio $\left[\mathrm{Mn}^{2+}\right]_{1 / 2} /\left[\mathrm{Mg}^{2+}\right]_{1 / 2}$ would decrease for thio-substituted P4-P6 relative to wild-type P4-P6). Further, rescue of inner-sphere metal-ion ligand perturbations would not be apparent at only a single rescuing $\mathrm{Mn}^{2+}$ concentration, as was used in the prior study (Basu and Strobel 1999), if the added $\mathrm{Mn}^{2+}$ were insufficient to overcome a strong destabilizing effect from disruption of these metal-ion interactions.

\section{$\mathrm{Mg}^{2+}$ - and $\mathrm{Mn}^{2+}$-induced folding of phosphorothioate- substituted P4-P6 in $20 \mathrm{mM} \mathrm{Na}^{+}$}

We first investigated folding of the two outer-sphere phosphorothioate-substituted P4-P6 RNAs, G188 $R_{\mathrm{P}}$ PS and G163 $R_{\mathrm{P}}$ PS, in the $20 \mathrm{mM} \mathrm{Na}{ }^{+}$background (Fig. 6C,D). With sufficient $\mathrm{Mg}^{2+}$, both constructs yield the same protection patterns as unmodified P4-P6 (left). Subdomain and tertiary protections for the phosphorothioates (open squares and open circles, respectively) appear over a narrow $\mathrm{Mg}^{2+}$ concentration range, analogous to the apparent single cooperative folding transition observed for unmodified P4-P6 in $\mathrm{Mg}^{2+}$, but at approximately twofold higher $\mathrm{Mg}^{2+}$ midpoints and with lower apparent Hill coefficients compared with unmodified P4-P6, reflecting decreased folding stability (Table 3A). 
In $\mathrm{Mn}^{2+}$, these modified P4-P6 RNAs exhibit separate folding transitions for subdomain formation and overall tertiary structure formation, as is observed for the unmodified RNA (Fig. 6C,D, right). The $\left[\mathrm{Mn}^{2+}\right]_{1 / 2}$ value for formation of the subdomain is increased relative to unmodified P4-P6, but formation of the final tertiary structure is not significantly affected (Fig. 6C,D, right; Tables $3 \mathrm{~A}, 3 \mathrm{~B})$. Even though the subdomain is destabilized, it still folds at concentrations lower than those required for overall tertiary folding, so the overall tertiary folding of these variants is unaffected (Table $3 \mathrm{~B})\left(\left[\mathrm{Mn}^{2+}\right]_{1 / 2}=0.3-0.4\right.$ $\mathrm{mM})$. Thus, a destabilizing effect on formation of the subdomain manifests as an effect on acquisition of overall tertiary structure in $\mathrm{Mg}^{2+}$, as folding of the subdomain is coupled to overall folding in $\mathrm{Mg}^{2+}$, but has no effect on overall folding in $\mathrm{Mn}^{2+}$ because subdomain folding is complete at lower $\mathrm{Mn}^{2+}$ concentrations than overall tertiary structure formation (Fig. 6A). The destabilizing effect in $\mathrm{Mg}^{2+}$ and
A

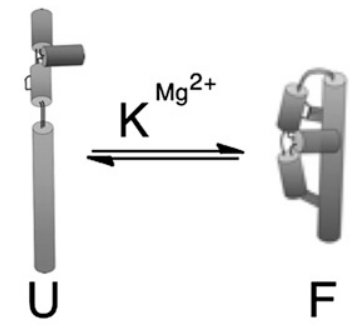

B

Unmodified

C

G188 $R_{\mathrm{P}}$

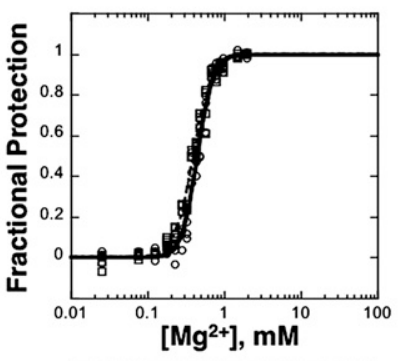

D

G163 $R_{\mathrm{P}}$

E

A184 $R_{\mathrm{p}}$
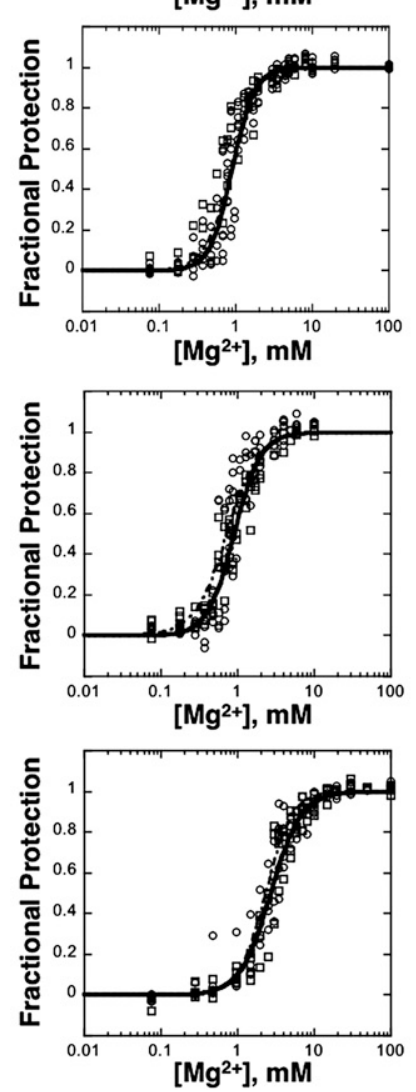
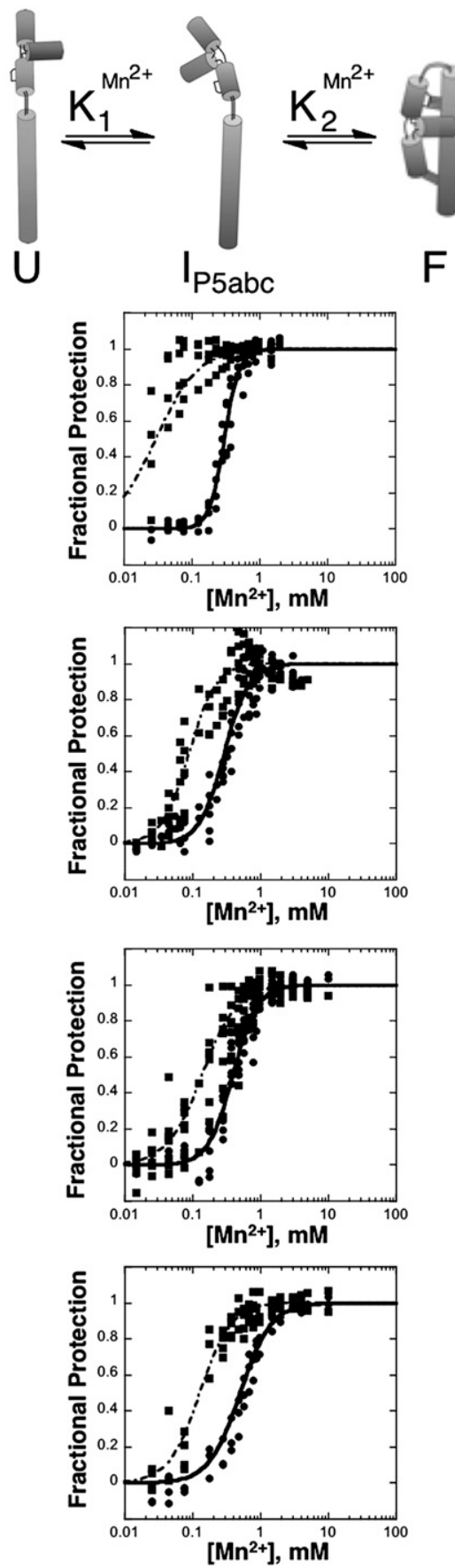

FIGURE 6. (Continued on next page) 
the absence of such an effect in $\mathrm{Mn}^{2+}$ corresponds to an apparent rescue of tertiary folding (Fig. 7A), but a rigorous appraisal requires accurately taking into account the additional intermediate observed in $\mathrm{Mn}^{2+}$. Complexities from this previously unknown intermediate account for the small, but significant apparent rescue of these outer-sphere constructs observed previously by native gel mobility assays that monitor primarily the global compaction associated with tertiary folding (Basu and Strobel 1999). Analogously, metal-ion rescue of catalysis can be misleading if the same reaction steps are not monitored throughout the comparisons (Shan and Herschlag 2000; Hougland et al. 2005).

The three inner-sphere constructs $\left(\mathrm{A} 184 R_{\mathrm{P}} \mathrm{PS}, \mathrm{A} 184 S_{\mathrm{P}}\right.$ PS, A184 $\mathrm{PS}_{2}$ ) also exhibit the same regions of protection as unmodified P4-P6 when folded in a background of $20 \mathrm{mM}$ $\mathrm{Na}^{+}$with sufficient divalent metal ion (data not shown). Like unmodified P4-P6, these constructs appear to fold in $\mathrm{Mg}^{2+}$ via a single transition, with subdomain and tertiary protections appearing over narrow concentration ranges (Fig. $6 \mathrm{E}-\mathrm{G}$, left; Table $3 \mathrm{~A}$ ). However, the associated midpoints occur at a six- to 10 -fold higher $\mathrm{Mg}^{2+}$ concentration compared with unmodified P4-P6. As with the outer-sphere phosphorothioates, the increased folding midpoints reflect a destabilization of folding in $\mathrm{Mg}^{2+}$, and the effects are greater than the effects from the outer-sphere thio substitutions (Fig. 7A).

Also as for the outer-sphere metal ions, the folding pathway in $\mathrm{Mn}^{2+}$ is different from that in $\mathrm{Mg}^{2+}$, and this difference leads to apparent rescue. Figure 6E-G (right) shows the two transitions for folding in $\mathrm{Mn}^{2+}$. As with the outer-sphere substitutions, the inner-sphere thio substitutions have a destabilizing effect on subdomain formation (closed squares) (cf. Fig. 6, C and D), but this transition still occurs at lower $\mathrm{Mn}^{2+}$ concentrations than tertiary folding (Fig. 6E-G, right, closed squares vs. closed circles), resulting in the observed subdomain folding intermediate. As described above for the outer-sphere thio substitutions, the higher $\left[\mathrm{Mg}^{2+}\right]_{1 / 2}$ coupled with the absence of an effect on $\left[\mathrm{Mn}^{2+}\right]_{1 / 2}$ for overall tertiary folding leads to apparent rescue (Fig. 7A). This apparent rescue is larger than that observed for the outer-sphere residues, but only because the inner-sphere substitutions have a larger destabilizing effect than do the outer-sphere substitutions. Any substitution or mutation that has a larger effect on subdomain formation without an additional destabilizing effect on the overall tertiary structure formation (i.e., affecting U-to$\mathrm{I}_{\mathrm{P} 5 \mathrm{abc}}$ without affecting the $\mathrm{I}_{\mathrm{P} 5 \mathrm{abc}}$-to-F transition) would give a still larger apparent rescue. The apparent rescue arises from the inappropriate thermodynamic comparison of folding that occurs via two different pathways-in $\mathrm{Mg}^{2+}$, from $\mathrm{U}$ to $\mathrm{F}$, and in $\mathrm{Mn}^{2+}$, from $\mathrm{I}_{\mathrm{P} 5 \mathrm{abc}}$ to $\mathrm{F}$ - and, therefore, need not have any relationship to rescue via stronger $\mathrm{Mn}^{2+}$-sulfur interactions.

As with the simpler $2 \mathrm{M} \mathrm{NaCl}$ data, quantitative evaluation of metal-ion rescue in lower monovalent salt concentration requires calculating and comparing freeenergy differences induced by thio modification for identical states in both $\mathrm{Mg}^{2+}$ and $\mathrm{Mn}^{2+}$ (Scheme 1). To resolve the complexity associated with different transition path-
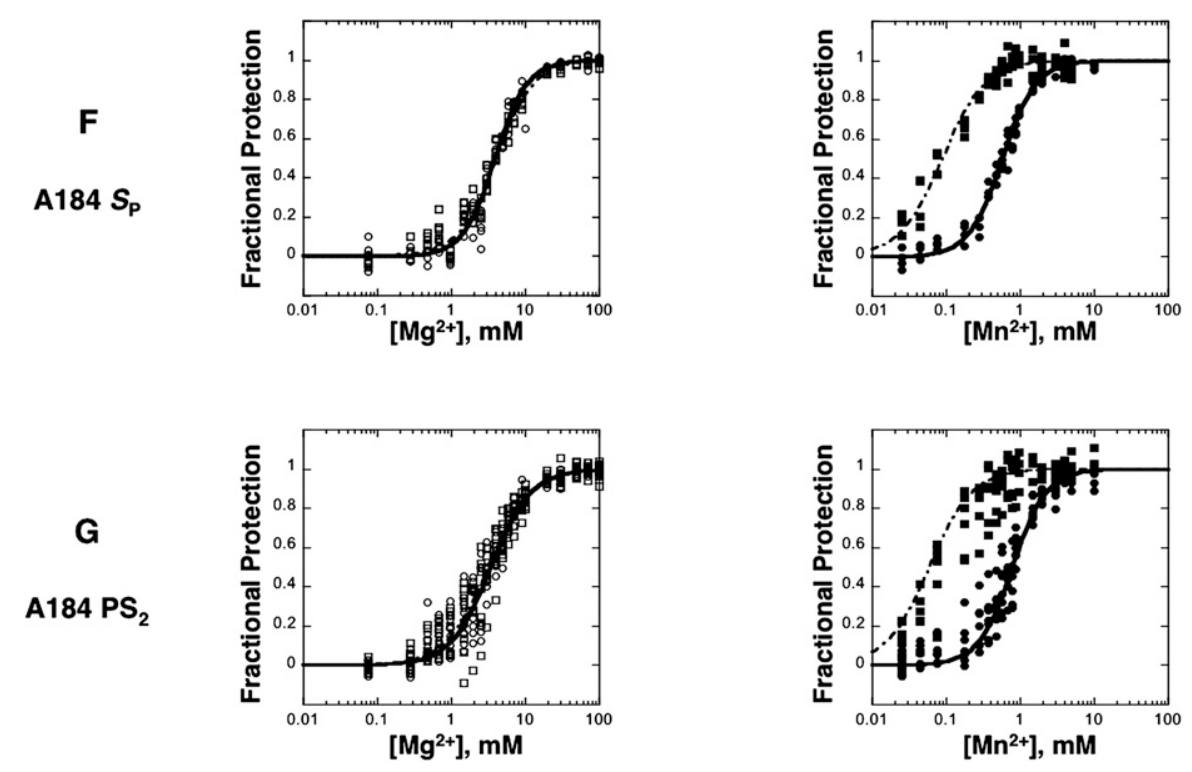

FIGURE 6. $\mathrm{Mg}^{2+}$ - or $\mathrm{Mn}^{2+}$-induced folding of $\mathrm{P} 4-\mathrm{P} 6$ variants in a background of $20 \mathrm{mM} \mathrm{Na}^{+}$. Folding of unmodified $\mathrm{P} 4-\mathrm{P} 6$ in $\mathrm{Mg}^{2+}$ follows an apparent two-state transition modeled as U-to-F $(A$, left), in which both subdomain protections $(B-G$, left, open squares and dashed curves) and tertiary protections $\left(B-G\right.$, left, open circles and solid curves) appear over approximately the same $\mathrm{Mg}^{2+}$ concentration range. In contrast, folding in $\mathrm{Mn}^{2+}$ follows the three-state transition U-to- $\mathrm{I}_{\mathrm{P} 5 \mathrm{abc}}$-to-F $(A$, right $)$, in which the subdomain protections $(B-G$, right, closed squares and dashed curves) appear at lower concentrations than the protections associated with formation of tertiary structure $(B-G$, right, closed circles and solid curves). Data points and curve fits were obtained for the subdomain and tertiary protections analogously to the procedure described for Figure 3. 
TABLE 3A. $\mathrm{Mg}^{2+}$-induced folding in $20 \mathrm{mM} \mathrm{Na}^{+}$

\begin{tabular}{lccccccc}
\hline & & \multicolumn{3}{c}{ Subdomain } & & \multicolumn{2}{c}{ Tertiary } \\
Construct & Ligand type & {$\left[\mathrm{Mg}^{2+}\right]_{1 / 2}(\mathrm{mM})$} & $n_{\text {Hill }}$ & & {$\left[\mathrm{Mg}^{2+}\right]_{1 / 2}(\mathrm{mM})$} & $n_{\text {Hill }}$ \\
\hline Unmodified & & $0.40 \pm 0.01$ & $3.6 \pm 0.2$ & & $0.44 \pm 0.01$ & $4.3 \pm 0.1$ \\
G188 $R_{\mathrm{P}}$ & OS & $0.88 \pm 0.09$ & $2.6 \pm 0.9$ & & $0.9 \pm 0.1$ & $3.0 \pm 0.7$ \\
$\mathrm{G} 163 R_{\mathrm{P}}$ & OS & $0.74 \pm 0.09$ & $2.1 \pm 0.2$ & & $0.9 \pm 0.1$ & $2.5 \pm 0.3$ \\
$\mathrm{~A} 184 R_{\mathrm{P}}$ & IS & $2.38 \pm 0.05$ & $2.5 \pm 0.1$ & & $2.7 \pm 0.6$ & $2.2 \pm 0.4$ \\
$\mathrm{~A} 184 S_{\mathrm{P}}$ & IS & $4.1 \pm 0.1$ & $1.7 \pm 0.3$ & & $3.9 \pm 0.2$ & $2.0 \pm 0.1$ \\
$\mathrm{~A} 184 \mathrm{PS}_{2}$ & IS & $3.2 \pm 0.5$ & $1.5 \pm 0.5$ & & $3.4 \pm 0.5$ & $1.6 \pm 0.3$ \\
\hline
\end{tabular}

$\mathrm{NaCl}$ conditions (Table 2), due to the summation of free energies over an additional transition in the $\mathrm{Mn}^{2+}$ titrations. For one of the constructs (A184 $R_{\mathrm{P}} \mathrm{PS}$ ), we cannot yet ascertain whether the measured rescue effect is greater than its associated error. Nevertheless, given these errors, the values in low monovalent salt and high monovalent salt background are in agreement, providing evidence for congruence between these biochemical metal-ion dissection experiments and the inner-

ways in $\mathrm{Mg}^{2+}$ and $\mathrm{Mn}^{2+}$, we calculated free-energy differences for the same overall process U-to-F. To resolve complexities associated with changing apparent Hill coefficients in modified RNAs, we analyzed the data in the general thermodynamic framework derived above based on global fits of the Hill coefficient across all variants (model 2 ; see Fig. 8 for the corresponding $n_{\mathrm{Hill}}$ vs. $\left[\mathrm{M}^{2+}\right]_{1 / 2}$ plots). The results of these analyses are summarized in Figure 7, B and $\mathrm{C}$ and Table 4, and demonstrate $\mathrm{Mn}^{2+}$ rescue of the inner- but not outer-sphere ligands.

Figure 7B shows the overall folding free energies (between states U-to-F) for each construct in $\mathrm{Mg}^{2+}$ and $\mathrm{Mn}^{2+}$, taking into account the single-transition vs. two-transition thermodynamics in the two conditions, respectively. The values in $\mathrm{Mg}^{2+}$ (Fig. 7B, left; Table $4, \mathrm{Mg}^{2+}, \mathrm{U}-$ to-F) are obtained from the single folding isotherms shown in Figure 6, B-G (left). The values in $\mathrm{Mn}^{2+}$ (Fig. 7B, right; Table 4, $\mathrm{Mn}^{2+}$ ) require summing the free energies from the two sets of folding isotherms (Fig. 6B-G, right), representing the U-to-I $\mathrm{I}_{\mathrm{P} 5 \mathrm{abc}}$ step (closed squares and dashed lines) and the $\mathrm{I}_{\mathrm{P} 5 \mathrm{abc}}$-to-F step (closed circles and solid lines) to yield the total free-energy difference for U-to-F. Figure 7C plots these differences in the folding free energies in $\mathrm{Mg}^{2+}$ vs. $\mathrm{Mn}^{2+}$ to allow rescue to be evaluated. As in the analysis of the simpler $2 \mathrm{M} \mathrm{NaCl}$ data above, similar values of $\Delta \Delta \mathrm{G}$ in $\mathrm{Mn}^{2+}$ vs. $\mathrm{Mg}^{2+}$ were observed for the outer-sphere substitutions G188 $R_{\mathrm{P}}$ PS and G163 $R_{\mathrm{P}}$ PS, giving no evidence of metal-ion rescue. Further, smaller $\Delta \Delta \mathrm{G}$ values in $\mathrm{Mn}^{2+}$ vs. $\mathrm{Mg}^{2+}$ for inner-sphere thio substitutions (A184 $R_{\mathrm{P}}$ PS, A184 $S_{\mathrm{P}} \mathrm{PS}$, A184 $\mathrm{PS}_{2}$ ) provide thermodynamic evidence for rescue of inner-sphere metalion interactions in these experiments. The quantitative values for the metal rescue free-energy differences $\Delta \Delta \Delta \mathrm{G}$ are $0.45 \pm$ $0.58(P=0.2),-0.66 \pm 0.63(P=0.9)$, $0.71 \pm 0.67(P=0.1), 1.48 \pm 0.65(P=$ $0.01)$, and $1.34 \pm 0.64(P=0.02) \mathrm{kcal}$ $\mathrm{mol}^{-1}$ for the modifications G188 $R_{\mathrm{P}} \mathrm{PS}$, G163 $R_{\mathrm{P}}$ PS, A184 $S_{\mathrm{P}}$ PS, A184 $R_{\mathrm{P}}$ PS, and $\mathrm{A} 184 \mathrm{PS}_{2}$, respectively (Table 4). These values have larger errors than the results obtained in the simplifying $2 \mathrm{M}$ sphere/outer-sphere nature of the RNA ligands from crystallography.

\section{SUMMARY AND IMPLICATIONS}

\section{Metal-ion rescue: Successes and lingering concerns}

Metal-ion rescue experiments have provided a powerful experimental approach for developing models of catalysis by ribozymes and for evaluating the functional relevance of structural models (Wang et al. 1999; Hougland et al. 2006; Nelson and Uhlenbeck 2006). Elucidation of the network of interactions mediated by metal ions and their ligands within ribozyme active sites has relied on the assumption that sites of rescue reveal ligands that occupy the inner coordination sphere of the metal ion. This interpretation follows logically from the known stronger coordination of rescuing metal ions to sulfur than oxygen. While the absence of rescue, a negative result, cannot be used to provide evidence against a direct metal-ion interaction, and while rescue can occur from recruitment of a new interaction not present in the wild-type/cognate pair, metal-ion rescue experiments have been used extensively with functional RNAs, and the results have been predictive of further functional and structural results (Wang et al. 1999; Adams et al. 2004; Guo et al. 2004; Golden et al. 2005; Hougland et al. 2006; Nelson and Uhlenbeck 2006). For example, quantitative metal-ion rescue studies provided evidence for a single catalytic metal ion that bridged positions $20 \AA$
TABLE 3B. $\mathrm{Mn}^{2+}{ }_{-}$induced folding in $20 \mathrm{mM} \mathrm{Na}^{+}$

\begin{tabular}{lccccccc}
\hline & & \multicolumn{3}{c}{ Subdomain } & & \multicolumn{2}{c}{ Tertiary } \\
\cline { 3 - 4 } Construct & Ligand type & {$\left[\mathrm{Mn}^{2+}\right]_{1 / 2}(\mathrm{mM})$} & $n_{\text {Hill }}$ & & {$\left[\mathrm{Mn}^{2+}\right]_{1 / 2}(\mathrm{mM})$} & $n_{\text {Hill }}$ \\
\hline Unmodified & & $0.03 \pm 0.01$ & $1.4 \pm 0.2$ & & $0.30 \pm 0.03$ & $3.9 \pm 0.2$ \\
$\mathrm{G} 188 R_{\mathrm{P}}$ & OS & $0.09 \pm 0.02$ & $2.2 \pm 0.3$ & & $0.29 \pm 0.04$ & $2.4 \pm 0.8$ \\
$\mathrm{G} 163 R_{\mathrm{P}}$ & OS & $0.14 \pm 0.01$ & $1.7 \pm 0.2$ & & $0.39 \pm 0.02$ & $2.4 \pm 0.8$ \\
$\mathrm{~A} 184 R_{\mathrm{P}}$ & IS & $0.13 \pm 0.01$ & $1.9 \pm 0.7$ & & $0.50 \pm 0.02$ & $1.9 \pm 0.1$ \\
$\mathrm{~A} 184 S_{\mathrm{P}}$ & IS & $0.09 \pm 0.01$ & $1.5 \pm 0.1$ & & $0.57 \pm 0.02$ & $1.9 \pm 0.1$ \\
$\mathrm{~A} 184 \mathrm{PS}_{2}$ & IS & $0.06 \pm 0.01$ & $1.5 \pm 0.2$ & & $0.78 \pm 0.09$ & $1.9 \pm 0.2$ \\
\hline
\end{tabular}




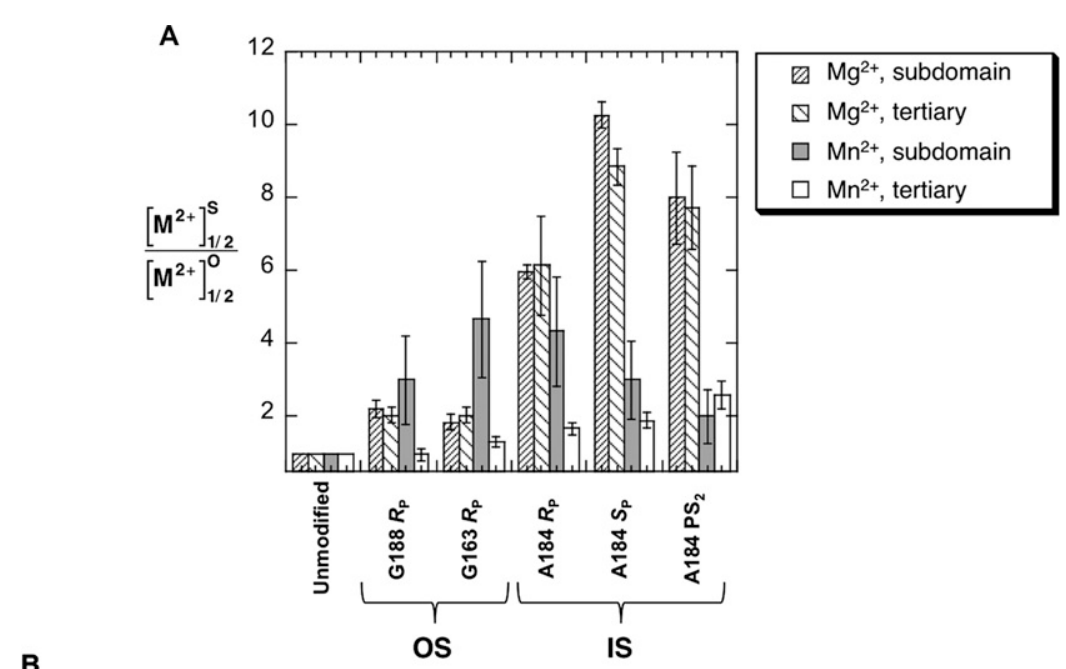

B
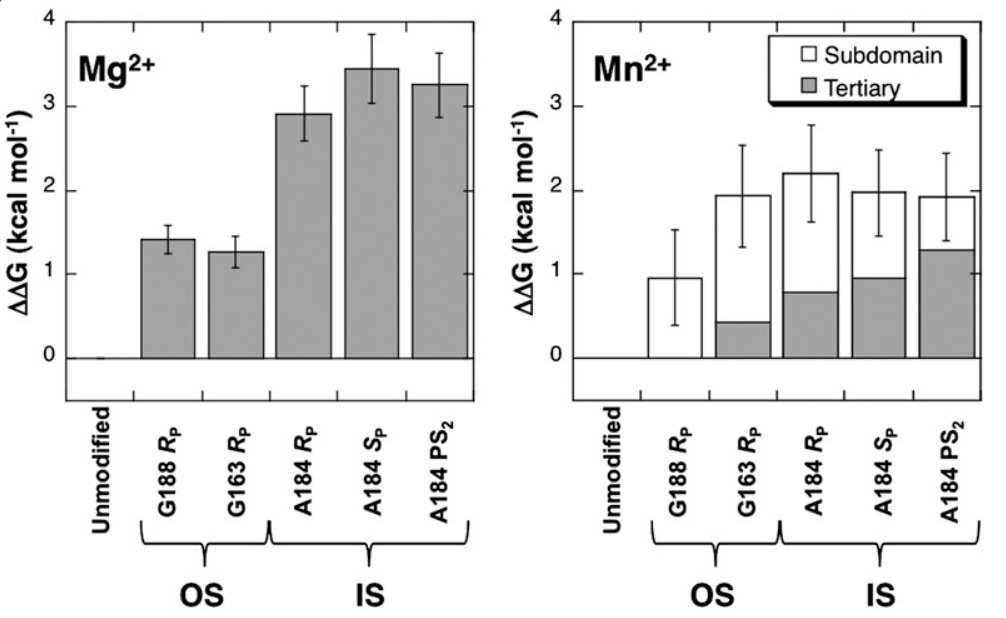

C

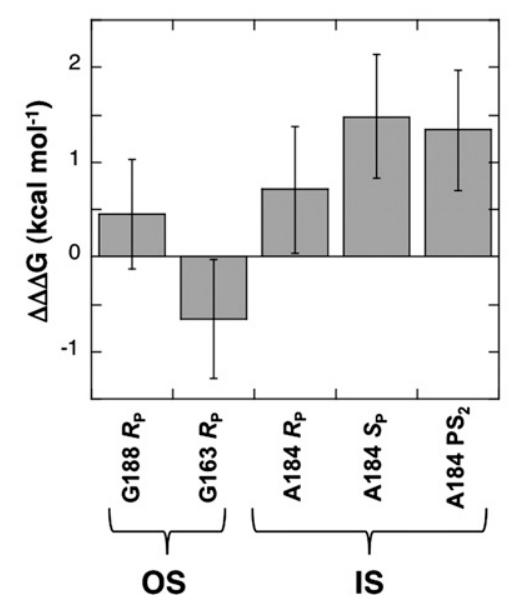

FIGURE 7. (A) Divalent metal-ion midpoint ratios of P4-P6 variants folded in either $\mathrm{Mg}^{2+}$ or $\mathrm{Mn}^{2+}$ in a background of $20 \mathrm{mM} \mathrm{Na}^{+}$, separated into subdomain and tertiary folding midpoints (OS: outer-sphere metal-ion ligand; IS: inner-sphere metal-ion ligand). (B) Calculated $\Delta \Delta \mathrm{G}$ values (relative to unmodified P4-P6) associated with $\mathrm{Mg}^{2+}$-induced (left) and $\mathrm{Mn}^{2+}$-induced (right) folding of P4-P6 phosphorothioate variants with respect to unmodified P4-P6. The values were calculated according to a thermodynamic framework in which the Hill coefficient is assumed to vary linearly with the divalent metal-ion concentration (model 2, Supplemental Material). The values for $\mathrm{Mn}^{2+}$ are arranged in a stacked plot that reflects the sum of the contributions from the separate $\mathrm{U}-$ to- $\mathrm{I}_{\mathrm{P} 5 \mathrm{abc}}$ (subdomain) and $\mathrm{I}_{\mathrm{P} 5 \mathrm{abc}}$-to-F (tertiary) folding transitions. (C) Calculated $\Delta \Delta \Delta \mathrm{G}$ values associated with $\mathrm{Mg}^{2+}$ - vs. $\mathrm{Mn}^{2+}$-induced folding of phosphorothioate-substituted P4-P6 variants in a background of $20 \mathrm{mM} \mathrm{Na}^{+}$. apart in hammerhead ribozyme X-ray structures (Wang et al. 1999), and subsequent X-ray structures of more active forms of the hammerhead provided strong support for this proposed conformational transition and metal-ion binding site (Martick and Scott 2006; Nelson and Uhlenbeck 2006). Extensive studies of group I ribozyme catalysis provided evidence for three active site metal ions and multiple ligand interactions, with all but one of these interactions supported by X-ray structural studies (Shan et al. 1999; Guo et al. 2004; Golden et al. 2005; Stahley and Strobel 2005; Hougland et al. 2006). In this case the structural evidence for two metal ions remains to be resolved with the functional evidence for three metal ions; it is possible that this case presents a rare example of metal-ion recruitment upon thio substitution (Hougland et al. 2006).

The observation from a previous nucleotide analog interference mapping (NAIM) analysis that $\mathrm{Mn}^{2+}$ appeared to suppress P4-P6 folding defects caused by sulfur substitution at outer-sphere ligands challenged the "standard" interpretation of metal-ion rescue experiments (Basu and Strobel 1999). It was possible that the combination of sulfur substitution with $\mathrm{Mn}^{2+}$ supplanted outersphere interactions between $\mathrm{Mg}^{2+}$ and the phosphate oxygen with inner-sphere interactions between $\mathrm{Mn}^{2+}$ and sulfur, engendered by the longer sulfur-phosphorus bond coupled with the longer sulfur- $\mathrm{Mn}^{2+}$ coordination distance. Alternatively, the apparent rescue might have reflected limitations associated with the native gel assay of folding, the single rescuing conditions used, or the thermodynamic assumptions underlying the analysis of the results.

We first used simplifying conditions, investigating P4-P6 folding and rescue in a high background concentration of monovalent cation. We previously showed that these conditions essentially saturate the ion atmosphere with monovalent cations, thereby simplifying divalent metal-ion-dependent folding such that the observed Hill slope of two corresponds precisely to the uptake of two metal ions 

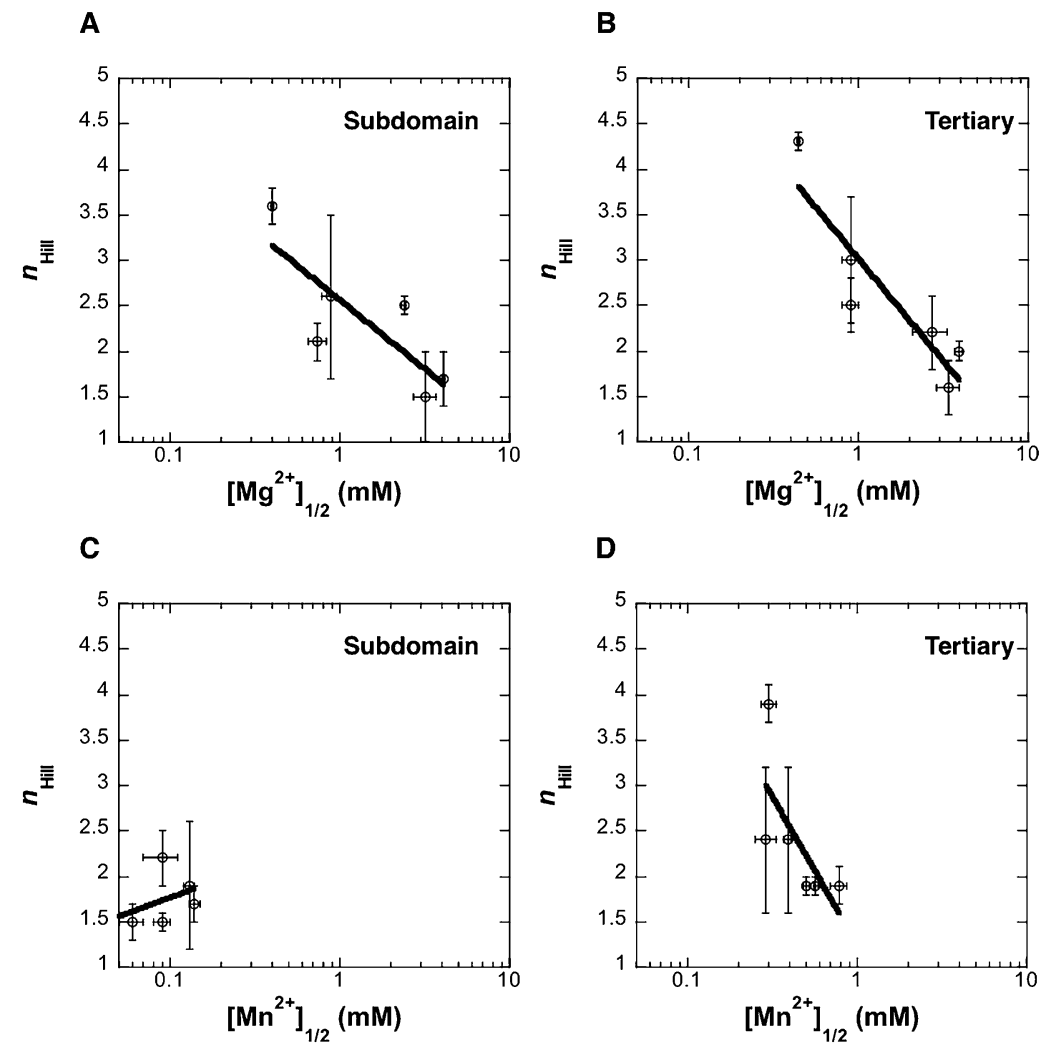

\section{D}

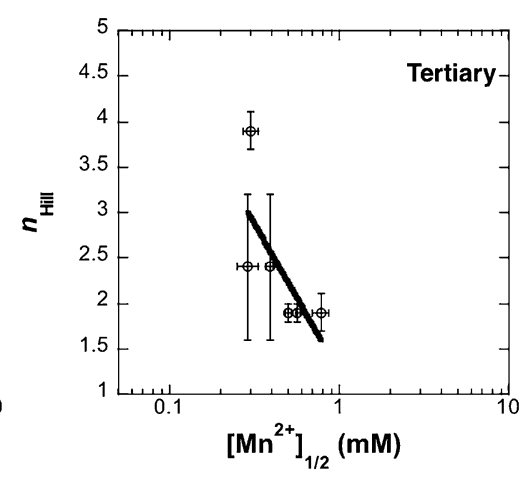

FIGURE 8. Linear fits to midpoint and Hill coefficient data according to model 2 (Equation 6) for folding of P4-P6 variants in $\mathrm{Mg}^{2+}(A, B)$ and in $\mathrm{Mn}^{2+}(C, D)$ in a background of $20 \mathrm{mM}$ $\mathrm{Na}^{+}$. (Data from Table 3.)

upon folding (Das et al. 2005b). At the time, we presumed that these two metal ions corresponded to site-bound metal ions in the P4-P6 crystallographic model, likely the most highly coordinated metal ions within the core of the P5abc domain (Fig. 1C, left). The rescue results here provide strong and direct support for this hypothesis and further reveal the identity of these metal ions.

While the simplifying high monovalent concentration conditions have been powerful for P4-P6 and for some other systems, not all RNAs will be as well behaved under these conditions, and it is desirable to also investigate RNAs under more physiologic conditions that allow more normal interactions with proteins and other binding partners. We also wished to investigate rescue under low-salt conditions to provide a more direct comparison to and test of the prior study that had called into question the ability of rescue experiments to discriminate between inner- and outersphere structural metal ions.

We found that the thermodynamic folding pathway differed in $\mathrm{Mg}^{2+}$ vs. $\mathrm{Mn}^{2+}$ in this low monovalent salt concentration background. In $\mathrm{Mn}^{2+}$, we observed stabilization and accumulation of a folding intermediate corresponding to the P5abc subdomain of P4-P6 $\left(\mathrm{I}_{\mathrm{P} 5 \mathrm{abc}}\right)$, a structure that contains the two metal-ion binding sites identified above and has previously been shown to fold independently (Murphy and Cech 1993; Wu and Tinoco 1998; Silverman et al. 1999; Zheng et al. 2001). The presence of two different folding pathways subverts simple thermodynamic analysis of the rescue experiments and was a key element limiting the prior data interpretation. This limitation is akin to the potential to be misled in rescue experiments that probe catalysis when different reaction steps are followed or different rate-limiting steps occur for the constructs being compared (Shan and Herschlag 2000; Hougland et al. 2005). By obtaining residue-by-residue folding isotherms via hydroxyl radical footprinting (Fig. 6) and by developing an approach to compare folding free energies under common conditions, we were able to determine the thermodynamics for the overall folding process and to demonstrate rescue of inner-sphere, but not outersphere ligands. Our findings underscore the importance of developing explicit thermodynamic models and carrying out complete thermodynamic characterizations.

Our results show that metal-ion rescue experiments can be successfully applied to identify ligands of structural

TABLE 4. Folding free energy differences of unmodified vs. phosphorothioate-substituted P4-P6 in $20 \mathrm{mM} \mathrm{Na}^{+}$

\begin{tabular}{|c|c|c|c|c|c|c|}
\hline \multirow[b]{3}{*}{ Construct } & \multirow[b]{3}{*}{ Ligand type } & \multicolumn{4}{|c|}{$\Delta \Delta \mathrm{G}\left(\mathrm{kcal} \mathrm{mol}^{-1}\right)$} & \multirow{3}{*}{$\begin{array}{l}\Delta \Delta \Delta \mathrm{G}(\mathrm{U} \rightarrow \mathrm{F}) \\
\left(\mathrm{kcal} \mathrm{mol}^{-1}\right)\end{array}$} \\
\hline & & \multirow{2}{*}{$\begin{array}{l}\mathrm{Mg}^{2+} \\
\mathrm{U} \rightarrow \mathrm{F}\end{array}$} & \multicolumn{3}{|c|}{$\mathrm{Mn}^{2+}$} & \\
\hline & & & $U \rightarrow I_{\text {P5abc }}$ & $\mathrm{I}_{\mathrm{P} 5 \mathrm{abc}} \rightarrow \mathrm{F}$ & $U \rightarrow F$ & \\
\hline G188 $R_{\mathrm{P}}$ & OS & $1.41 \pm 0.17$ & $1.02 \pm 0.47$ & $-0.06 \pm 0.30$ & $0.96 \pm 0.56$ & $0.45 \pm 0.58$ \\
\hline G163 $R_{\mathrm{P}}$ & OS & $1.27 \pm 0.18$ & $1.50 \pm 0.57$ & $0.43 \pm 0.18$ & $1.93 \pm 0.60$ & $-0.66 \pm 0.63$ \\
\hline $\mathrm{A} 184 R_{\mathrm{P}}$ & IS & $2.91 \pm 0.33$ & $1.42 \pm 0.55$ & $0.78 \pm 0.19$ & $2.20 \pm 0.58$ & $0.71 \pm 0.67$ \\
\hline $\mathrm{A} 184 S_{\mathrm{P}}$ & IS & $3.45 \pm 0.41$ & $1.02 \pm 0.47$ & $0.95 \pm 0.21$ & $1.97 \pm 0.51$ & $1.48 \pm 0.65$ \\
\hline $\mathrm{A} 184 \mathrm{PS}_{2}$ & IS & $3.25 \pm 0.38$ & $0.62 \pm 0.40$ & $1.29 \pm 0.32$ & $1.91 \pm 0.52$ & $1.34 \pm 0.64$ \\
\hline
\end{tabular}


metal ions, analogous to the use of rescue experiments to identify catalytic interactions of metal ions. As an increasing number of RNAs with biological roles other than catalysis are being identified, tools to dissect folding and metal ion and other interactions within folded structures will be increasingly important. Recent advances that increase the throughput and precision in analysis of nucleic acid footprinting data (Das et al. 2005a, 2010; Merino et al. 2005; Yoon et al. 2011), as well as the conceptual approaches introduced herein, should greatly facilitate analysis of these RNAs.

\section{MATERIALS AND METHODS}

\section{Cloning}

The plasmid pUC19 $\Delta$ C209 P4-P6 was a gift from Kara Juneau and Tom Cech and encodes full-length $\Delta$ C209 P4-P6 with a 5' T7 promoter sequence, cloned between the EcoRI and XbaI restriction sites of the pUC19 vector. The plasmid pUC19 102-178 $\mathrm{HH}$ was a gift of Scott K. Silverman and encodes nucleotides 102178 of $\mathrm{P} 4-\mathrm{P} 6$, followed by a hammerhead ribozyme cleavage sequence, cloned between the EcoRI and HindIII restriction sites of pUC19 (Silverman and Cech 1999). Two additional plasmids, pUC19 175-261 $\Delta$ C209 and pUC19 200-261 $\Delta$ C209, encoding T7 transcripts 175-261 and 200-261, respectively, of $\Delta$ C209 P4-P6 were constructed via PCR from pUC19 $\Delta$ C209 P4-P6. The PCR products for these constructs were cloned into pUC19 between the EcoRI and XbaI restriction sites. The sequences of all constructs were verified by forward and reverse automated sequencing.

\section{RNA preparation}

Linearization of all plasmids was accomplished by overnight digestion with EarI, except for pUC19 102-178 HH, which was linearized by overnight digestion with HindIII. Typical transcription reactions contained $40 \mathrm{mM}$ Tris- $\mathrm{HCl}(\mathrm{pH} 8), 25 \mathrm{mM} \mathrm{MgCl}_{2}$, $2 \mathrm{mM}$ spermidine, $0.01 \%$ Triton X-100, $4 \mathrm{mM}$ NTPs, $10 \mathrm{mM}$ DTT, $50 \mu \mathrm{g} / \mathrm{mL}$ linearized plasmid, 2 units/mL inorganic pyrophosphatase, and $84.6 \mu \mathrm{g} / \mathrm{mL}$ T7 RNA polymerase (prepared in the Piccirilli lab by Joseph Olvera). Transcription reactions of pUC19 102-178 $\mathrm{HH}$ included $30 \mathrm{mM} \mathrm{MgCl}_{2}$ to ensure sufficient hammerhead ribozyme cleavage (Silverman and Cech 1999). Transcription reactions that used pUC19 175-261 $\Delta$ C209 or pUC19 200-261 $\Delta$ C209 included $10 \mathrm{mM}$ GMP to ensure the presence of a $5^{\prime}$ monophosphate. All transcriptions were carried out at $37^{\circ} \mathrm{C}$ for $2 \mathrm{~h}$. Transcripts were purified via $8 \%$ denaturing PAGE and electroeluted into TE pH 7.5, extracted with 25:25:1 (v/v/v) phenol/ chloroform/isoamyl alcohol, precipitated with ethanol, and stored at $-20^{\circ} \mathrm{C}$.

RNA nucleotides $102-153$ of $\Delta$ C209 P4-P6 were obtained by digestion of full-length $\Delta$ C209 P4-P6 RNA with the 10-23 DNAzyme 5'-AAGGCCATCTCAAAGGGCTAGCTACAACGATTCCCCTGAG ACTTG-3', purchased from Integrated DNA Technologies (Santoro and Joyce 1997). About $16 \mathrm{nmol}$ of $\Delta \mathrm{C} 209$ P4-P6 RNA were combined with $25 \mathrm{nmol}$ of DNAzyme, heated at $95^{\circ} \mathrm{C}$ for $3 \mathrm{~min}$, and placed on ice for $1 \mathrm{~min}$. Following the addition of 5x DNAzyme buffer $(750 \mathrm{mM} \mathrm{NaCl}, 200 \mathrm{mM}$ tris- $\mathrm{HCl}$ at $\mathrm{pH} 8)$, the mixture was incubated at $37^{\circ} \mathrm{C}$ for $30 \mathrm{~min}$ to allow hybridization. To initiate cleavage, $\mathrm{MgCl}_{2}$ was added to a final concentration of $60 \mathrm{mM}$, and the reaction was allowed to proceed at $37^{\circ} \mathrm{C}$ for $5 \mathrm{~h}$. The reaction was then treated with 25 units of RNase-free DNase (Promega) for $1 \mathrm{~h}$ at $37^{\circ} \mathrm{C}$ to remove the DNAzyme. Following phenol/chloroform/ isoamyl alcohol extraction and ethanol precipitation, the desired 52 -nt product was purified via 6\% dPAGE.

As a result of $3^{\prime}$-end processing, the RNA molecules 102-178 and 102-153 contained $3^{\prime}$-terminal $2^{\prime}, 3^{\prime}$-cyclic phosphate groups. To remove these groups, the RNAs were treated with T4 polynucleotide kinase (T4 PNK; New England Biolabs) based on a protocol described previously (Silverman and Cech 1999). Briefly, $\sim 5-10$ nmol of RNA were incubated with 50-100 units of T4 PNK in $1 \mathrm{x}$ kinase buffer $(50 \mathrm{mM}$ tris- $\mathrm{HCl}$ at $\mathrm{pH} 7.5,10 \mathrm{mM} \mathrm{MgCl} 2,5$ $\mathrm{mM} \mathrm{DTT}$ ) at $37^{\circ} \mathrm{C}$ for $5 \mathrm{~h}$. The RNAs were then extracted with phenol/chloroform/isoamyl alcohol and precipitated with ethanol.

Synthetic monophosphorothioate RNA oligonucleotides 179199 A184 PS and 154-174 G163 PS of $\Delta$ C209 P4-P6 were purchased from Dharmacon, Inc. Phosphorothioate diastereomers were separated via anion exchange HPLC (Frederiksen and Piccirilli 2009). The RNA oligonucleotide 179-199 containing a phosphorodithioate linkage 5' of nucleotide A184 was synthesized on a $1-\mu \mathrm{mol}$ scale on an Expedite 8909 nucleic acid synthesizer. Except at position 183, this oligo was synthesized with standard RNA phosphoramidites. At position 183, an adenosine phosphorothioamidite was coupled that had been synthesized based on methods described previously (Petersen and Nielsen 1990). Following a 30-min coupling or double coupling step, the initial dichlorobenzyl phosphorothioate linkage was converted to a phosphorodithioate linkage by a 400 -sec oxidation with $5 \%$ sulfur in $1: 1(\mathrm{v} / \mathrm{v})$ pyridine/carbon disulfide or with $0.05 \mathrm{M}$ solution of sulfurizing reagent II in 2:3 (v/v) pyridine/acetonitrile. After synthesis of the full-length oligo had been completed, the dichlorobenzyl protecting group was removed by treatment with 1:1:2 $(\mathrm{v} / \mathrm{v} / \mathrm{v})$ thiophenol/triethylamine/dioxane at room temperature for $2 \mathrm{~h}$. The solid support was then washed three times each with methanol and diethyl ether and allowed to dry. Base deprotection and cleavage from the solid support was achieved by treatment with $3: 1(\mathrm{v} / \mathrm{v})$ ammonium hydroxide/ethanol for $2 \mathrm{~h}$ at $55^{\circ} \mathrm{C}$. Following evaporation of the ethanolic ammonia solution, the 2 -silyl protecting groups were removed by treatment with a $6: 3: 4$ $(\mathrm{v} / \mathrm{v} / \mathrm{v})$ solution of $\mathrm{N}$-methyl pyrrolidinone/triethylamine/triethylamine trihydrofluoride at $65^{\circ} \mathrm{C}$ for $1.5 \mathrm{~h}$ (Wincott et al. 1995). The deprotected phosphorodithioate oligonucleotide was then purified by anion-exchange HPLC and could be clearly distinguished from the $R_{\mathrm{P}}$ and $S_{\mathrm{P}}$ monothioate species, which elute earlier from the column than the dithioate. The mass of the phosphorodithioate oligo was confirmed by MALDI mass spectrometry (calculated for M-H: 6787.9, measured 6787.1).

\section{Modified P4-P6 RNAs prepared by splint ligation}

Schemes describing construction of phosphorothioate-modified RNAs are shown in Supplemental Figure S1. When possible, synthetic phosphorothioate oligonucleotides were ordered with $5^{\prime}$-phosphate groups (Dharmacon). The phosphorodithioate oligo was phosphorylated on its $5^{\prime}$ end by using T4 PNK and ATP. RNAs were joined by using standard DNA splint ligation methods (Moore and Sharp 1992). In a typical reaction, $5 \mathrm{nmol}$ of each component (splint, 5' RNA and $3^{\prime}$ RNA) were combined in TE $\mathrm{pH} 7.5\left(10 \mathrm{mM}\right.$ tris- $\mathrm{HCl}$ at $\mathrm{pH} 7.5,1 \mathrm{mM} \mathrm{Na}_{2}$ EDTA $\mathrm{pH}$ 8), 
heated to $90^{\circ} \mathrm{C}$ for $4 \mathrm{~min}$, placed on ice for $1 \mathrm{~min}$, and incubated at $37^{\circ} \mathrm{C}$ for $30 \mathrm{~min}$. To this mixture were added $10 \mathrm{x}$ ligation buffer, 500 pmol T4 DNA ligase (prepared in the Piccirilli lab by Joseph Olvera) and water so that the final volume was as small as possible while still keeping the final concentration of glycerol below 5\%. Beside RNA, splint, and T4 DNA ligase, the final ligation reaction contained $40 \mathrm{mM}$ tris $-\mathrm{HCl}(\mathrm{pH} \mathrm{7.5)}, 10 \mathrm{mM}$ $\mathrm{MgCl}_{2}, 10 \mathrm{mM}$ DTT, $1 \mathrm{mM} \mathrm{ATP}$, and $0.05 \mathrm{mg} / \mathrm{mL}$ bovine serum albumin. Ligation reactions were allowed to proceed for $4-5 \mathrm{~h}$ at $37^{\circ} \mathrm{C}$, after which time the DNA splint was removed by treatment with RQ1 RNase-free DNase (Promega, Inc.). Following phenol/ chloroform/isoamyl alcohol extraction and ethanol precipitation, the ligation products were purified via $6 \% \mathrm{dPAGE}$ and subsequent electroelution into TE $\mathrm{pH}$ 7.5. Ligation junctions were confirmed by alkaline hydrolysis and T1 ladders, while iodine cleavage was used to confirm the positions of the phosphorothioate linkages.

\section{Fe-EDTA footprinting}

Full-length $\Delta$ C209 P4-P6 molecules were 5 '-end labeled by treatment with $\left[\gamma-{ }^{32} \mathrm{P}\right] \mathrm{ATP}$ and T4 PNK, gel purified by $6 \%$ dPAGE, eluted passively overnight into TE $\mathrm{pH} 7.5$ at $4^{\circ} \mathrm{C}$, extracted with phenol/chloroform/isoamyl alcohol, and precipitated with ethanol. Prior to storage at $-20^{\circ} \mathrm{C}$, labeled RNAs were resuspended in water to an activity of $\sim 100,000 \mathrm{cpm} / \mu \mathrm{L}$ to minimize autoradiolysis.

A mix was prepared and distributed in $8-\mu \mathrm{L}$ aliquots so that each footprinting reaction initially contained $1 \mu \mathrm{L}$ of $5^{\prime}$-end labeled RNA, $1 \mu \mathrm{L}$ of $500 \mathrm{mM}$ Na-MOPS ( $\mathrm{pH} 7$ ), and $6 \mu \mathrm{L}$ of water. Reactions carried out in the presence of $2 \mathrm{M} \mathrm{NaCl}$ contained $4 \mu \mathrm{L}$ of $5 \mathrm{M} \mathrm{NaCl}$ and $2 \mu \mathrm{L}$ of water. Following the addition of 1 $\mu \mathrm{L}$ of a $10 \mathrm{x}$ solution of $\mathrm{MgCl}_{2}$ or $\mathrm{MnCl}_{2}$, the RNA was allowed to fold for $\sim 15 \mathrm{~min}$ at room temperature.

A $10 \mathrm{x}$ footprinting reagent was prepared separately that contained $1 \mathrm{mM} \mathrm{Fe}\left(\mathrm{NH}_{4}\right)_{2}\left(\mathrm{SO}_{4}\right)_{2}, 1.25 \mathrm{mM}$ EDTA $(\mathrm{pH} 8)$, and $60 \mathrm{mM}$ sodium ascorbate. To initiate the footprinting reaction, $1 \mu \mathrm{L}$ of this reagent was added to each aliquot to a final volume of $10 \mu \mathrm{L}$ so that each reaction contained labeled RNA, $50 \mathrm{mM} \mathrm{Na-MOPS} \mathrm{(} \mathrm{pH} 7$ ), $2 \mathrm{M} \mathrm{NaCl}$ where appropriate, varying concentrations of $\mathrm{MgCl}_{2}$ or $\mathrm{MnCl}_{2}, 0.1 \mathrm{mM} \mathrm{Fe}\left(\mathrm{NH}_{4}\right)_{2}\left(\mathrm{SO}_{4}\right)_{2}, 0.125 \mathrm{mM}$ EDTA (pH 8), and $6 \mathrm{mM}$ sodium ascorbate. The reaction was allowed to proceed for $30 \mathrm{~min}$ at room temperature, and was quenched by the addition of $5 \mu \mathrm{L}$ of a thiourea stop solution (9 M urea, $300 \mathrm{mM}$ thiourea, $0.1 \%$ each xylene cyanol and bromophenol blue).

The footprinting reactions ( $7 \mu \mathrm{L}$ of each) were fractionated on $8 \%-8.5 \%$ denaturing gels. The gels were dried, exposed to storage phosphor screens, and scanned on a Typhoon Trio imager (GE Healthcare). Gels were quantified using the SAFA program (Das et al. 2005a). Importantly, for residues that become protected only upon addition of divalent metal ions, no significant difference in cleavage intensity was found between samples folded in $2 \mathrm{M} \mathrm{NaCl}$ alone and samples folded in $20 \mathrm{mM} \mathrm{Na}^{+}$alone. This result argues against a significant effect of contaminating divalent metal ions in the $2 \mathrm{M} \mathrm{NaCl}$ samples.

\section{Initial data analysis and curve fitting}

Regions of protection from hydroxyl radical cleavage were identified as follows. Footprinting in $2 \mathrm{M} \mathrm{NaCl}$ yielded clear divalent metal-ion-dependent protections at nucleotides 164, 176-177, $180-182$, and 187 , corresponding to folding of the P5abc subdo- main. In $20 \mathrm{mM} \mathrm{Na}^{+}$, protections at nucleotides $152-153$ and $200-$ 202 , and at $176-177$ and $180-182$, were chosen to reflect tertiary and subdomain folding, respectively. At each nucleotide position, each individual footprinting experiment generated a set of intensities whose values decreased in proportion to the extent of protection. The intensity data were fit initially to a four-parameter Hill equation as described in the Supplemental Material (Equation S1) and were subsequently normalized based on these fits. Data for protected regions spanning multiple nucleotides (e.g., 152-153 or 180-182) were averaged for each experiment. All of the data corresponding to a given folding transition derived from two to four independent experiments per RNA construct were then plotted on the same graph. For example, each plot in Figure 3 contains all data associated with nucleotides 164, 176-177, 180-182, and 187 (when available) obtained from each footprinting experiment conducted in $2 \mathrm{M} \mathrm{NaCl}$. We then took the average of all of the protection data at each divalent metal-ion concentration and fit the resulting points to the Hill equation to produce the final curves shown in Figures 3 and 6. The midpoints and Hill coefficients derived from these curves were then used to determine $\Delta \Delta \mathrm{G}$ and $\Delta \Delta \Delta \mathrm{G}$ values for the constructs according to procedures outlined in the Supplemental Material. Finally, an independent analysis based on a rigorous likelihood formalism was carried out and gave indistinguishable results for the thermodynamic parameters and their errors (see Supplemental Material, Supplemental Figs. S3-S5, and Supplemental Tables S3, S4).

\section{SUPPLEMENTAL MATERIAL}

Supplemental material is available for this article.

\section{ACKNOWLEDGMENTS}

We thank Kara Juneau, Tom Cech, and Scott Silverman for gifts of reagents and Joseph Olvera for technical assistance. We also thank Dr. Tobin Sosnick, Dr. Jonathan Staley, and Dr. Carl Correll for helpful discussions, and members of the Piccirilli lab for comments on the manuscript. This work was supported by NIH grants to D.H. (GM 49243) and J.A.P. (GM 088656), and by a Jane Coffin Childs Foundation Fellowship (to R.D.). J.K.F. was also supported by the University of Chicago Medical Scientist Training Program (5 T32 GM07281).

Received June 14, 2011; accepted January 17, 2012.

\section{REFERENCES}

Adams PL, Stahley MR, Kosek AB, Wang JM, Strobel SA. 2004. Crystal structure of a self-splicing group I intron with both exons. Nature 430: 45-50.

Anderson CF, Record MT Jr. 1990. Ion distributions around DNA and other cylindrical polyions: theoretical descriptions and physical implications. Annu Rev Biophys Biophys Chem 19: 423465.

Bai Y, Greenfeld M, Travers KJ, Chu VB, Lipfert J, Doniach S, Herschlag D. 2007. Quantitative and comprehensive decomposition of the ion atmosphere around nucleic acids. J Am Chem Soc 129: 14981-14988.

Basu S, Strobel SA. 1999. Thiophilic metal ion rescue of phosphorothioate interference within the Tetrahymena ribozyme P4-P6 domain. RNA 5: 1399-1407. 
Bukhman YV, Draper DE. 1997. Affinities and selectivities of divalent cation binding sites within an RNA tertiary structure. J Mol Biol 273: $1020-1031$.

Cate JH, Gooding AR, Podell E, Zhou KH, Golden BL, Kundrot CE, Cech TR, Doudna JA. 1996. Crystal structure of a group I ribozyme domain: Principles of RNA packing. Science 273: $1678-1685$.

Cate JH, Hanna RL, Doudna JA. 1997. A magnesium ion core at the heart of a ribozyme domain. Nat Struct Biol 4: 553-558.

Chen Y, Li X, Gegenheimer P. 1997. Ribonuclease P catalysis requires $\mathrm{Mg}^{2+}$ coordinated to the pro- $R_{\mathrm{P}}$ oxygen of the scissile bond. Biochemistry 36: 2425-2438.

Christian EL. 2005. Identification and characterization of metal ion binding by thiophilic metal ion rescue. In Handbook of RNA biochemistry (ed. RK Hartmann). Wiley-VCH Verlag GmbH \& Co., Weinheim, Germany.

Chu VB, Bai Y, Lipfert J, Herschlag D, Doniach S. 2008. A repulsive field: advances in the electrostatics of the ion atmosphere. Curr Opin Chem Biol 12: 619-625.

Costa FF. 2010. Non-coding RNAs: Meet thy masters. Bioessays 32: 599-608.

Darby MK, Trayer IP. 1983. Metal-nucleotide structure at the active sites of the mammalian hexokinases. Eur J Biochem 129: 555-560.

Das R, Laederach A, Pearlman SM, Herschlag D, Altman RB. 2005a. SAFA: Semi-automated footprinting analysis software for highthroughput quantification of nucleic acid footprinting experiments. RNA 11: 344-354.

Das R, Travers KJ, Bai Y, Herschlag D. 2005b. Determining the $\mathrm{Mg}^{2+}$ stoichiometry for folding an RNA metal ion core. J Am Chem Soc 127: 8272-8273.

Das R, Karanicolas J, Baker D. 2010. Atomic accuracy in predicting and designing noncanonical RNA structure. Nat Methods 7: 291294.

Draper DE, Grilley D, Soto AM. 2005. Ions and RNA folding. Annu Rev Biophys Biomol Struct 34: 221-243.

Fang X, Pan T, Sosnick TR. 1999. A thermodynamic framework and cooperativity in the tertiary folding of a $\mathrm{Mg}^{2+}$-dependent ribozyme. Biochemistry 38: 16840-16846.

Forconi M, Herschlag D. 2009. Use of phosphorothioates to identify sites of metal-ion binding in RNA. Methods Enzymol 468: 311-333.

Forconi M, Lee J, Lee JK, Piccirilli JA, Herschlag D. 2008. Functional identification of ligands for a catalytic metal ion in group I introns. Biochemistry 47: 6883-6894.

Frederiksen JK, Piccirilli JA. 2009. Separation of RNA phosphorothioate oligonucleotides by HPLC. Meth Enzymol 468: 289-309.

Garcia HG, Kondev J, Orme N, Theriot JA, Phillips R. 2011. Thermodynamics of biological processes. Methods Enzymol 492: 27-59.

Golden BL, Kim H, Chase E. 2005. Crystal structure of a phage Twort group I ribozyme-product complex. Nat Struct Mol Biol 12: 82-89.

Gordon PM, Fong R, Piccirilli JA. 2007. A second divalent metal ion in the group II intron reaction center. Chem Biol 14: 607-612.

Guo F, Gooding AR, Cech TR. 2004. Structure of the Tetrahymena ribozyme: Base triple sandwich and metal ion at the active site. Mol Cell 16: 351-362.

Horton TE, Clardy DR, DeRose VJ. 1998. Electron paramagnetic resonance spectroscopic measurement of $\mathrm{Mn}^{2+}$ binding affinities to the hammerhead ribozyme and correlation with cleavage activity. Biochemistry 37: 18094-18101.

Hougland JL, Kravchuk AV, Herschlag D, Piccirilli JA. 2005. Functional identification of catalytic metal ion binding sites within RNA. PLoS Biol 3: 1536-1548.

Hougland JL, Piccirilli JA, Forconi M, Lee J, Herschlag D. 2006. How the group I intron works: A case study of RNA structure and function. In The RNA world: The nature of modern RNA suggests a prebiotic RNA world, 3rd edition (ed. RF Gesteland et al.). Cold Spring Harbor Laboratory Press, Cold Spring Harbor, NY.

Jaffe EK, Cohn M. 1978. Divalent cation-dependent stereospecificity of adenosine $5^{\prime}-\mathrm{O}$-(2-thiotriphosphate) in the hexokinase and pyruvate kinase reactions. The absolute stereochemistry of the diastereoisomers of adenosine $5^{\prime}$-O-(2-thiotriphosphate). J Biol Chem 253: 4823-4825.

Juneau K, Cech TR. 1999. In vitro selection of RNAs with increased tertiary structure stability. RNA 5: 1119-1129.

Juneau K, Podell E, Harrington DJ, Cech TR. 2001. Structural basis of the enhanced stability of a mutant ribozyme domain and a detailed view of RNA-solvent interactions. Structure 9: 221-231.

Lee CS, O'Sullivan WJ. 1985. The interaction of phosphorothioate analogues of ATP with phosphomevalonate kinase. Kinetic and ${ }^{31} \mathrm{P}$ NMR studies. J Biol Chem 260: 13909-13915.

Leipply D, Draper DE. 2010. Dependence of RNA tertiary structural stability on $\mathrm{Mg}^{2+}$ concentration: interpretation of the Hill equation and coefficient. Biochemistry 49: 1843-1853.

Leipply D, Lambert D, Draper DE. 2009. Ion-RNA interactions thermodynamic analysis of the effects of mono- and divalent ions on RNA conformational equilibria. Methods Enzymol 469: 433-463.

Manning GS. 1977a. Limiting laws and counterion condensation in polyelectrolyte solutions. IV. The approach to the limit and the extraordinary stability of the charge fraction. Biophys Chem 7: 95-102.

Manning GS. 1977b. Theory of the delocalized binding of $\mathrm{Mg}$ (II) to DNA: preliminary analysis for low binding levels. Biophys Chem 7: 141-145.

Manning GS. 1978. Limiting laws and counterion condensation in polyelectrolyte solutions. V. Further development of the chemical model. Biophys Chem 9: 65-70.

Martick M, Scott WG. 2006. Tertiary contacts distant from the active site prime a ribozyme for catalysis. Cell 126: 309-320.

Merino EJ, Wilkinson KA, Coughlan JL, Weeks KM. 2005. RNA structure analysis at single nucleotide resolution by selective 2 '-hydroxyl acylation and primer extension (SHAPE). J Am Chem Soc 127: 4223-4231.

Misra VK, Draper DE. 1998. On the role of magnesium ions in RNA stability. Biopolymers 48: 113-135.

Moore MJ, Sharp PA. 1992. Site-specific modification of pre-RNA: the 2'-hydroxyl groups at the splice sites. Science 256: 992-997.

Murphy FL, Cech TR. 1993. An independently folding domain of RNA tertiary structure within the Tetrahymena ribozyme. Biochemistry 32: 5291-5300.

Murphy FL, Cech TR. 1994. GAAA tetraloop and conserved bulge stabilize tertiary structure of a group I intron domain. J Mol Biol 236: 49-63.

Nelson JA, Uhlenbeck OC. 2006. When to believe what you see. Mol Cell 23: 447-450.

Pecoraro VL, Rendina AR, Cleland WW. 1985. Determination of the screw sense specificity of bovine liver fructokinase. Biochemistry 24: $1619-1622$.

Petersen KH, Nielsen J. 1990. Chemical synthesis of dimer ribonucleotides containing internucleotidic phosphorodithioate linkages. Tetrahedron Lett 31: 911-914.

Piccirilli JA, Vyle JS, Caruthers MH, Cech TR. 1993. Metal-ion catalysis in the Tetrahymena ribozyme reaction. Nature 361: 8588.

Rook MS, Treiber DK, Williamson JR. 1999. An optimal $\mathrm{Mg}^{2+}$ concentration for kinetic folding of the Tetrahymena ribozyme. Proc Natl Acad Sci 96: 12471-12476.

Santoro SW, Joyce GF. 1997. A general purpose RNA-cleaving DNA enzyme. Proc Natl Acad Sci 94: 4262-4266.

Schwans JP, Cortez CN, Olvera JM, Piccirilli JA. 2003. 2'-mercaptonucleotide interference reveals regions of close packing within folded RNA molecules. J Am Chem Soc 125: 10012-10018.

Shan SO, Herschlag D. 2000. An unconventional origin of metal-ion rescue and inhibition in the Tetrahymena group I ribozyme reaction. RNA 6: 795-813.

Shan SO, Yoshida A, Sun SG, Piccirilli JA, Herschlag D. 1999. Three metal ions at the active site of the Tetrahymena group I ribozyme. Proc Natl Acad Sci 96: 12299-12304.

Silverman SK, Cech TR. 1999. Energetics and cooperativity of tertiary hydrogen bonds in RNA structure. Biochemistry 38: 8691-8702. 
Silverman SK, Zheng MX, Wu M, Tinoco I, Cech TR. 1999. Quantifying the energetic interplay of RNA tertiary and secondary structure interactions. RNA 5: 1665-1674.

Sontheimer EJ, Sun S, Piccirilli JA. 1997. Metal ion catalysis during splicing of premessenger RNA. Nature 388: 801-805.

Stahley MR, Strobel SA. 2005. Structural evidence for a two-metalion mechanism of group I intron splicing. Science 309: 15871590.

Takamoto K, Das R, He Q, Doniach S, Brenowitz M, Herschlag D, Chance MR. 2004. Principles of RNA compaction: Insights from the equilibrium folding pathway of the P4-P6 RNA domain in monovalent cations. J Mol Biol 343: 1195-1206.

Travers KJ, Boyd N, Herschlag D. 2007. Low specificity of metal ion binding in the metal ion core of a folded RNA. RNA 13: 12051213.

Wang S, Karbstein K, Peracchi A, Beigelman L, Herschlag D. 1999. Identification of the hammerhead ribozyme metal ion binding site responsible for rescue of the deleterious effect of a cleavage site phosphorothioate. Biochemistry 38: 14363-14378.
Weinstein LB, Jones BC, Cosstick R, Cech TR. 1997. A second catalytic metal ion in group I ribozyme. Nature 388: 805-808.

Weiss JN. 1997. The Hill equation revisited: uses and misuses. FASEB J 11: 835-841.

Wincott F, DiRenzo A, Shaffer C, Grimm S, Tracz D, Workman C, Sweedler D, Gonzalez C, Scaringe S, Usman N. 1995. Synthesis, deprotection, analysis and purification of RNA and ribozymes. Nucleic Acids Res 23: 2677-2684.

Wu M, Tinoco I Jr. 1998. RNA folding causes secondary structure rearrangement. Proc Natl Acad Sci 95: 11555-11560.

Yoon S, Kim J, Hum J, Kim H, Park S, Kladwang W, Das R. 2011. HiTRACE: high-throughput robust analysis for capillary electrophoresis. Bioinformatics 27: 1798-1805.

Yoshida A, Sun SG, Piccirilli JA. 1999. A new metal ion interaction in the Tetrahymena ribozyme reaction revealed by double sulfur substitution. Nat Struct Biol 6: 318-321.

Zheng M, Wu M, Tinoco I Jr. 2001. Formation of a GNRA tetraloop in P5abc can disrupt an interdomain interaction in the Tetrahymena group I ribozyme. Proc Natl Acad Sci 98: 3695-3700. 

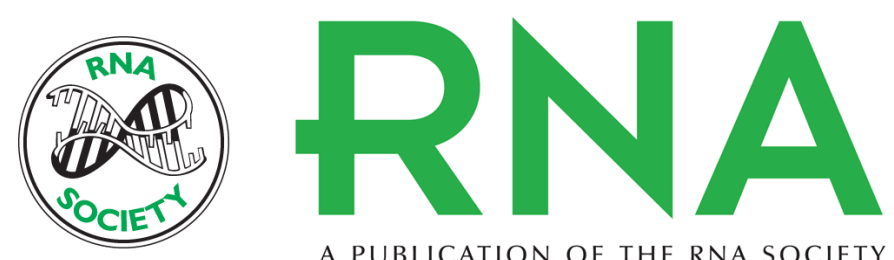

A PUBLICATION OF THE RNA SOCIETY

\section{Metal-ion rescue revisited: Biochemical detection of site-bound metal ions important for RNA folding}

John K. Frederiksen, Nan-Sheng Li, Rhiju Das, et al.

RNA 2012 18: 1123-1141 originally published online April 26, 2012

Access the most recent version at doi:10.1261/rna.028738.111

Supplemental
Material http://rnajournal.cshlp.org/content/suppl/2012/03/21/rna.028738.111.DC1

References This article cites 63 articles, 16 of which can be accessed free at: http://rnajournal.cshlp.org/content/18/6/1123.full.html\#ref-list-1

License

Email Alerting Receive free email alerts when new articles cite this article - sign up in the box at the Service top right corner of the article or click here. 